OPEN ACCESS

Edited by:

Javier Ochoa-Repáraz,

Eastern Washington University,

United States

Reviewed by:

Guangxun Meng,

Institut Pasteur of Shanghai (CAS),

China

Sung-Wook Hong

University of Minnesota, United States

*Correspondence:

Ping Gao

gaop@im.ac.cn

Fuping Zhang

zhangfp@im.ac.cn

${ }^{\text {t}}$ These authors have contributed equally to this work

Specialty section: This article was submitted to Mucosal Immunity,

a section of the journal

Frontiers in Immunology

Received: 07 September 2021 Accepted: 13 December 2021

Published: 27 January 2022

Citation:

Liu H, Gao P, Jia B, Lu N,

Zhu $B$ and Zhang $F$ (2022)

IBD-Associated Atg16L1T300A

Polymorphism Regulates Commensal

Microbiota of the Intestine.

Front. Immunol. 12:772189. doi: 10.3389/fimmu.2021.772189

\section{IBD-Associated Atg16L1T300A Polymorphism Regulates Commensal Microbiota of the Intestine}

\author{
Hongtao Liu ${ }^{1,2 \dagger}$, Ping Gao ${ }^{1 \star}$, Baoqian Jia ${ }^{1}, \mathrm{Na} \mathrm{Lu}{ }^{1}$, Baoli Zhu ${ }^{1,3}$ and Fuping Zhang ${ }^{1,3^{*}}$ \\ ${ }^{1}$ CAS Key Laboratory of Pathogenic Microbiology and Immunology, Institute of Microbiology, Chinese Academy of Sciences \\ (CAS), Beijing, China, ${ }^{2}$ College of Life Science, University of Chinese Academy of Sciences, Beijing, China, ${ }^{3}$ Department of \\ Savaid Medical School, University of Chinese Academy of Sciences, Beijing, China
}

The development of inflammatory bowel disease (IBD) is driven by the interaction among host genetics, microbiota, and the immune system of the entire digestive tract. Atg16L1T300A polymorphism is a genetic factor that confers increased risk for the pathogenesis of Crohn's disease. However, the exact contributions of Atg16L1T300A to intestinal mucosal homeostasis are not well understood. Here we show that Atg16L1T300A polymorphism impacts commensal bacterial flora in the intestine under a steady state. Analysis of intestinal bacteria from Atg16L1 ${ }^{\text {T300ATT300A }}$ mice showed that they harbored an altered microbiota in both the terminal ileum and colon compared to

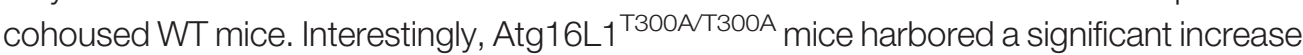
in the abundance of Tyzzerella, Mucispirillum, Ruminococcaceae, and Cyanobacteria which were known associated with IBD. Moreover, Akkermansia, a bacterium that is

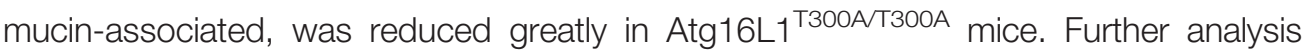

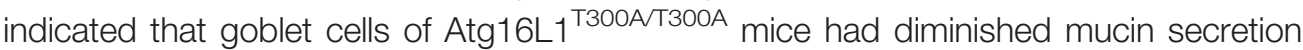
that resulted from defective autophagy. Finally, Atg16L $1^{\text {T300ATT300A }}$ mice developed more severe inflammation in the DSS colitis model than in WT mice. These results indicate that the altered microbiota in Atg16L1 ${ }^{\text {T300ATT300A }}$ mice might be an important factor that contributed to the risk of Atg16L1T300A carriers to Crohn's disease and supports a multihit disease model involving specific gene-microbe interactions.

Keywords: Atg16L1T300A, microbiota dysbiosis, goblet cells, autophagy, IBD - inflammatory bowel disease

\section{INTRODUCTION}

Inflammatory bowel disease (IBD), which includes Crohn's disease (CD) and ulcerative colitis (UC), is a chronic relapsing inflammatory disease characterized by impaired intestinal homeostasis and abnormal stress response (1). Chronic gut inflammation in IBD patients is also a potent risk factor for colorectal cancer, which is the second leading cause of cancer deaths with an estimated nearly $1,360,000$ new cases and 694,000 deaths per year and is increasing in incidence worldwide (2). The etiology of IBD is complex. Microbial dysbiosis, genetic susceptibility, and environmental factors have been associated with the development and progression of the disease (3), although the exact cause of $\mathrm{CD}$ remains largely undescribed. 
Trillions of bacteria living inside the gut form microbiota. The homeostasis of the gut microbiota is essential for numerous vital host physiological processes, including digestion of dietary factors, development of the gut immune system, and colonization resistance against incoming pathogens $(1,3)$. Dysbiosis of the gut microbiota, including alterations in frequency, diversity, and richness of microbial populations, has been associated with IBD pathogenesis $(4,5)$. Patients with IBD exhibit increases in the abundance of harmful taxa, or decreases in abundance of protective taxa. Research suggested a dynamic interplay between the microbiota and disease pathophysiology (6), but how dysbiosis manifests and, more specifically, how individual species are affected by host genetics are less well understood. Furthermore, numerous studies of the microbiota dysbiosis associated with IBD development have focused on the fecal samples; however, limited information is available regarding the composition of mucosaassociated microbiota and the role these microbiotas played during the IBD development.

It is widely accepted that the combination of host genetics and intestinal dysbiosis contributes to IBD. To date, genome-wide association studies (GWAS) have identified more than 230 IBDassociated susceptibility loci, a large fraction of which is associated with microbial defense pathways $(7,8)$. One of the most influential genes for CD susceptibility identified so far is the genetic variants at position 300 in the autophagy gene Atg16L1, resulting in a threonine-to-alanine substitution (T300A) in the C-terminal domain (8). Atg16L1, a central adaptor required for the formation of the matured autophagosome, plays a key role in mice's intestinal epithelium (9). Atg16L1T300A mutation introduces a caspase- 3 cleavage site in Atg16L1 protein that is associated with reduced levels of autophagy flux and increased risk of developing $\mathrm{CD}(10,11)$. Although much progress has been made regarding the mechanism by which Atg16L1 T300A is associated with IBD, little is known about Atg16L1 T300A on the microbiota community in the intestine.

In this study, we assessed the microbiome in cohoused WT and $\operatorname{Atg} 16 \mathrm{~L} 1^{\mathrm{T} 300 \mathrm{~A} / \mathrm{T} 300 \mathrm{~A}}$ mice using $16 \mathrm{~S}$ rRNA gene sequencing and found that $\operatorname{Atg} 16 \mathrm{~L} 1^{\mathrm{T} 300 \mathrm{~A} / \mathrm{T} 300 \mathrm{~A}}$ mice harbored an increased abundance of microbiota that was associated with IBD, while Akkermansia muciniphila, a beneficial microbiota, was decreased significantly. Moreover, Atg16L1 ${ }^{\mathrm{T} 300 \mathrm{~A} / \mathrm{T} 300 \mathrm{~A}}$ mice developed more severe inflammation in a dextran sodium sulfate (DSS) colitis model. Thus, our findings indicated that microbiota dysbiosis in $\operatorname{Atg} 16 \mathrm{L1}^{\mathrm{T} 300 \mathrm{~A} / \mathrm{T} 300 \mathrm{~A}}$ mice might be one of the important factors contributing to the increased susceptibility of IBD.

\section{MATERIALS AND METHODS}

\section{Mice}

Atg16L1 $1^{\mathrm{T} 300 \mathrm{~A} / \mathrm{T} 300 \mathrm{~A}}\left(\operatorname{Atg} 16 \mathrm{~L} 1^{\mathrm{f} / \mathrm{f}}\right.$ or T300A KI) mice on a C57BL/ 6J background have been described previously (10). Atg16 $\mathrm{L1}^{\mathrm{f} / \mathrm{f}}$ ERT2Cre ${ }^{+}$mice were generated by crossed Atg16 $11^{\mathrm{f} / \mathrm{f}}$ mice with ERT2Cre mice, which were treated with tamoxifen every other day for 4 times to activate ERT2Cre, and Atg16L1 was deleted to generate Atg16L1 KO mice. All mice within one experiment were cohoused for 4-5 weeks after weaning in the third week of birth to minimize differences between each line (12). All mice were bred and maintained in the SPF barrier at the Institute of Microbiology, Chinese Academy of Sciences (IMCAS). All animal studies were performed according to approved protocols from the IMCAS of Medicine Institutional Animal Care and Use Committee. The genotypes of all mice were genotyped with the following genotyping primers:

Atg16L1 ${ }^{\mathrm{T} 300 \mathrm{~A} / \mathrm{T} 300 \mathrm{~A}}$ :

5'-CCTGGAGCTGGGCAGTCAGGTTGGGCTCCATG-3'

5'-GCTGCTTCCCTGTCAGTCAACTGTG-3'

ERT2 ${ }^{\mathrm{Cre}}$ :

5'-AAAGTCGCTCTGAGTTGTTAT-3'

5'-GGAGCGGGAGAAATGGATATG-3'

5'-CCTGATCCTGGCAATTTCG-3'

\section{DSS-Induced Colitis and Experimental Design}

Cohoused, male and female, 7-8-week-old Atg16 $1^{\mathrm{T} 300 \mathrm{~A} / \mathrm{T} 300 \mathrm{~A}}$ mice and their littermate control mice were used. For mild experimental colitis induction, mice were administered with $1.5 \%$ DSS (M.W. = 36,000-50,000 Da; MP Biomedicals) in their drinking water for 7 days, followed by regular drinking water for 3 days. Body weight was monitored, with changes in body weight calculated relative to initial body weight. Postmortem whole colons were harvested by blunt dissection, and colon length was measured.

\section{Histological Staining Analysis}

Distal colon segments in the same defined region were collected carefully and were transferred immediately to $4 \%$ phosphatebuffered formaldehyde (4\% PFA) solution for $24 \mathrm{~h}$ and embedded in paraffin. Sections of $5 \mu \mathrm{m}$ were stained with hematoxylin and eosin (H\&E) and then scanned with a light microscope (Zeiss Axio Imager A2) for further histopathological analysis. At least three slides were randomly selected and observed by a blinded pathologist. The tissue damage of each colon was scored based on the degree of epithelial damage and inflammatory infiltrate in the mucosa, submucosa, and muscularis/serosa, as previously described (13).

\section{Whole-Mount Immunofluorescence Staining}

The isolated small intestine or colon was opened longitudinally after the adipose tissues were stripped off. Using a scissor, the intestine was cut into $2-3-\mathrm{cm}$ equal sections. Each section was placed onto a wax plate, and each end was pinned down so the section was slightly stretched with the mesenteric line uppermost; any excess mesentery was trimmed. Tissues were fixed in 4\% PFA for $1 \mathrm{~h}$ before being rinsed three times for $5 \mathrm{~min}$ in PBS. The tissues were flooded with fluorescein isothiocyanatelabeled $H$. pomatia lectin (Invitrogen, L11271) for $2 \mathrm{~h}$ at room temperature. Tissues were mounted on glass slides and examined under a Zeiss Axio Imager A2 fluorescence microscope with a $\times 10$ objective. 


\section{Fluorescence In Situ Hybridization}

Colon tissues were prepared for fluorescence in situ hybridization (FISH), analysis as previously described (14). Briefly, after mouse intestines were fixed in 4\% PFA, and after deparaffinization and rehydration in hybridization buffer $(0.9 \mathrm{M} \mathrm{NaCl}, 0.1 \%$ SDS, and 20 $\mathrm{mM}$ Tris- $\mathrm{HCl}, \mathrm{pH} 7.4$ ), the tissues were incubated 2 hours at $50^{\circ} \mathrm{C}$ in the dark with Alexa 532-conjugated Eubacteria EUB338 (5'GCTGCCTCCCGTAGGAGT-3') or non-EUB338 probe for bacterial 16S rRNA genes (15). The sections were then washed three times with a hybridization solution for $15 \mathrm{~min}$, counterstained with DAPI, and mounted. The sections were imaged with an inverted microscope (Leica SP8) using a Leica $\times 10$ objective. Distances between intestinal epithelial cells and luminal bacteria were quantified by using the ImageJ tool.

\section{PAS Staining}

Mouse distal ileum or colon samples were fixed in 4\% PFA in PBS for $24 \mathrm{~h}$, dehydrated, and embedded in paraffin. Tissue slices (5 $\mu \mathrm{m}$ in thickness) were mounted on positively charged glass and dewaxed.

For periodic acid-Schiff (PAS) staining, sections $(5 \mu \mathrm{m})$ were cut and stained with PAS. Briefly, the slides were incubated for 5 min in $0.5 \%$ periodic acid solution, washed with $\mathrm{ddH}_{2} \mathrm{O}$, and then incubated for $20 \mathrm{~min}$ in Schiff reagent, washed $5 \mathrm{~min}$ in tap water. The slides were then counterstained with hematoxylin for $1 \mathrm{~min}$, after which the slides were dehydrated, mounted, and observed with a light microscope (Zeiss Axio Imager A2).

\section{Transmission Electron Microscopy}

Sections of mouse intestines from euthanized mice were washed with ice-cold PBS and cut into pieces about $3 \mathrm{~mm}$ in length. Selected tissues were fixed in $2.5 \%$ glutaraldehyde and $2 \%$ paraformaldehyde in $0.1 \mathrm{M}$ sodium phosphate buffer (PB buffer, $\mathrm{pH} 7.4$ ) at $4^{\circ} \mathrm{C}$ overnight. Then, samples were rinsed 57 times in PB buffer, postfixed in $1 \%$ osmic acid for $2 \mathrm{~h}$, and washed 5-7 times in PB buffer. Dehydration was done with an acetone gradient followed by infiltration with Epon 812 resin and baked overnight at $60^{\circ} \mathrm{C}$. Hardened blocks were cut using a Leica Ultracut Ultramicrotome (Leica EM UC6) and stained using 2\% uranyl acetate and lead citrate. Images were obtained using a transmission electron microscope (JEM-1400) at $80 \mathrm{kV}$. Goblet cells were measured from five animals for each genotype.

\section{Isolation of Intestinal Epithelial Cells}

Epithelial cells were obtained from freshly isolated colons and flushed from both ends with sterile PBS. Colons were then opened longitudinally and washed with PBS. Mucus was removed by gently scraping the villus with a cover glass slide. Intestines were washed and incubated in $10 \mathrm{ml}$ PBS containing $30 \mathrm{mM}$ EDTA and $1.5 \mathrm{mM}$ DTT on ice for $20 \mathrm{~min}$ (16). Intestines were then removed and briefly washed in PBS and incubated in $10 \mathrm{ml}$ PBS containing $30 \mathrm{mM}$ EDTA at $37^{\circ} \mathrm{C}$ at $220 \mathrm{RPM}$ for $10 \mathrm{~min}$. The cells were subjected to 30 -s vigorous shaking, then centrifuged at $1,000 \mathrm{~g}$ for $5 \mathrm{~min}$ at $4^{\circ} \mathrm{C}$, washed in PBS, and then resuspended in PBS buffer. Cell pellets constituting isolated intestinal epithelial cell fractions were lysed for Western blot to detect Atg16L1 and LC3.

\section{Immunoblot}

Colonic epithelium cells were isolated as described above (16). Isolated cells were lysed in RIPA buffer with protease inhibitors and subjected to SDS-PAGE and transferred to polyvinylidene difluoride (PVDF) membranes. Then, PVDF membranes were blocked by exposure to PBST containing 5\% non-fat dry milk for $1 \mathrm{~h}$ at room temperature. The blocked membranes were probed by incubation with the indicated antibody at $4^{\circ} \mathrm{C}$ overnight. Proteins were detected with HRP-conjugated secondary antibody and visualized by ECL (GE). The following antibodies were used: anti-Atg16L1 (MBL, M150-3), anti-LC3 (Novus Biologicals, NB100-2331), and anti-actin (Santa Cruz Biotechnology, sc-8432).

\section{RNA Isolation and Gene Expression Analysis}

RNA was extracted from isolated colonic epitheliums with TRIzol Reagent (Invitrogen) following the manufacturer's instructions. cDNA was generated using a High-Capacity cDNA Reverse Transcription Kit (Applied Biosystems). Realtime PCR was performed using the SYBR Green Master Mix (Applied Biosystems) on an ABI 7500 thermal cycler in duplicate. Gene-expression values were calculated by using 2 $\triangle \triangle \mathrm{Ct}$ normalized to HPRT. Primers for quantitative PCR were used as follows:

Mouse-Muc2-F: ACGATGCCTACACCAAGGTC

Mouse-Muc2-R: TGATCTTCTGCATGTTCCCA

Mouse HPRT-F: GTCCCAGCGTCGTGATTAGC

Mouse HPRT-R: TGGCCTCCCATCTCCTTCA

\section{S rRNA Gene Sequencing}

Stool samples for $16 \mathrm{~S}$ rRNA amplicon surveys were collected into a $2-\mathrm{ml}$ sterile tube and stored at $-80^{\circ} \mathrm{C}$ prior to DNA extraction. Mucus scraping samples were collected as previously described (17). Briefly, following sacrifice of mice, the distal ileum and whole colon were excised and filleted open. Large fecal matter was gently removed if present, and a brushing of the colonic mucosal surface was performed to test for the mucosal-associated microbiome. Then, the collected fecal pellets and mucus scrapings were processed for DNA isolation according to the recommended manual (Qiagen). PCR amplification, library preparation, library-quality inspection, and quantification were performed, and the set TAG sequence was used to distinguish the samples. $16 \mathrm{~S}$ rRNA sequencing of the V4 region was performed on an Illumina HiSeq 2500 high-throughput sequencing platform to sequence the qualified libraries.

\section{Statistical Analysis}

Data are expressed as mean \pm SEM. Two groups were compared by using a non-parametric test analysis of variance followed by a Mann-Whitney test analysis. Multiple-comparison analyses were performed using one/two-way ANOVA followed by Tukey or Bonferroni post hoc tests using GraphPad Prism 7 (GraphPad Software Inc.). p $<0.05$ was considered as indicating a statistically significant difference. 


\section{RESULTS}

\section{Atg16L1 ${ }^{\text {T300A/T300A }}$ Mice Display a Slightly Different Microbial Composition in Fecal at a Steady State}

Previous studies have shown that IBD development is associated with dysbiosis (2). Atg16L1 is an autophagy gene involved in the handling of intracellular bacteria. Cells or mice bearing Atg16L1 T300A polymorphism have a reduced capacity of bacterial clearance $(10,18)$. Although it has been reported that the Atg16L1 T300A mutation is associated with alterations in gut microbiota, there is a lack of further detailed investigation, and the factors that contributed to altered gut microbiota have never been studied. Thus, to determine the effect of Atg16L1 T300A on commensal bacteria at a steady state, we performed experiments by using cohoused WT and Atg16L1 $1^{\mathrm{T} 300 \mathrm{~A} / \mathrm{T} 300 \mathrm{~A}}$ mice to reduce the influence of microbiome heritability as a confounding factor. Because fecal samples are widely used in mouse studies to survey the microbiome and its relationship to IBD, we first performed $16 \mathrm{~S}$ rRNA gene sequencing on feces of WT and Atg16L1 $1^{\text {T300A/T300A }}$ mice to determine the composition and diversity of the fecal associated microbiota. We found that the taxonomy-based analysis did not have broad alterations in the phylum and family composition of commensal bacteria between Atg16L1 $1^{\mathrm{T} 300 \mathrm{~A} / \mathrm{T} 300 \mathrm{~A}}$ and WT mice (Figures 1A, B), and alphadiversity analyses based on the Shannon index and Bray-Curtis distance also showed no significant differences between Atg16L1 $1^{\mathrm{T} 300 \mathrm{~A} / \mathrm{T} 300 \mathrm{~A}}$ mice and WT controls (Figure 1C). Next, we performed unweighted UniFrac PCoA analysis to investigate the differences in species complexity and structural alterations in gut microbial communities ( $\beta$-diversity), and we found a minor difference between the WT and Atg16L1 ${ }^{\text {T300A/T300A }}$ microbiotas (Figure 1D). Moreover, we applied the linear discriminant analysis (LDA) effect size (LEfSe) method for high-dimensional biomarker discovery to interpret the microbiota between $\operatorname{Atg} 16 \mathrm{~L} 1^{\mathrm{T} 300 \mathrm{~A} / \mathrm{T} 300 \mathrm{~A}}$ and WT commensal composition. We found nine differentially abundant taxonomic clades with an LDA score higher than 2.0, indicating that these bacteria significantly differ in WT and Atg16L1 $1^{\mathrm{T} 300 \mathrm{~A} / \mathrm{T} 300 \mathrm{~A}}$ mouse feces. Among the nine differentially abundant taxonomic clades, the opportunistic pathogens Ruminococcaceae and Cyanobacteria were enriched in Atg16L1 $1^{\mathrm{T} 300 \mathrm{~A} / \mathrm{T} 300 \mathrm{~A}}$ mice (Figure 1E) and have been reported to be increased in fecal samples from the mouse model of ulcerative colitis $(19,20)$ and in human patients of Crohn's disease (21). Thus, this finding indicated that the Atg16L1 T300A variant slightly influenced the microbial composition in fecal samples at a steady state.

\section{Alteration of Microbial Communities in the Mucosa of Atg16L1 $1^{\mathrm{T} 300 \mathrm{~A} / \mathrm{T} 300 \mathrm{~A}}$ Mice}

While fecal samples are the predominant material used for microbial community analysis, it may not be the ideal sample for analysis of the gut microbiome. Because IBD is characterized by a compromised mucosal barrier and inappropriate immune activation by commensals mislocalized to the mucosa (22), and bacteria reside in the colonic mucus gel layer, and the colonic mucus microbiome was more closely correlated with colitis severity than that of the alterations in the fecal microbiomes (23). Thus, investigating the microbial communities of the mucus layer may provide more important information that is key to understanding the mechanisms by which the Atg16L1 T300A variant affected CD development. In the next study, we investigated the interrelationship between the Atg16L1 T300A variant and the composition of microbiota in the ileum and colon mucosa of Atg16 $1^{\mathrm{T} 300 \mathrm{~A} / \mathrm{T} 300 \mathrm{~A}}$ and WT mice. For this end, colons and terminal ileum were isolated from WT and $\operatorname{Atg} 16 \mathrm{~L} 1^{\mathrm{T} 300 \mathrm{~A} / \mathrm{T} 300 \mathrm{~A}}$ mice, and the content was removed. Then, the mucosa scraping sample was collected and used to perform $16 \mathrm{~S}$ rRNA gene amplicon surveys to detect associated mucosal bacteria. The UniFrac PCoA analysis of microbial communities in the mucosa indicated that the overall microbiome diversity is comparable between WT and Atg16L1 ${ }^{\mathrm{T} 300 \mathrm{~A} / \mathrm{T} 300 \mathrm{~A}}$ mice (Figure S1A). Moreover, the relative taxa abundance is different in colon mucosa between the WT and $\operatorname{Atg} 16 \mathrm{~L} 1^{\mathrm{T} 300 \mathrm{~A} / \mathrm{T} 300 \mathrm{~A}}$ mice. The most abundant taxa at the phylum and family levels in the colon are shown in (Figures 2A, B). At the phylum level, the abundance of Firmicutes, Campilobacterota, and Deferribaterota was amplified, while Bacteroidetes was declined in Atg16L1 $1^{\mathrm{T} 300 \mathrm{~A} / \mathrm{T} 300 \mathrm{~A}}$ mice compared to that of the WT group. This observation was consistent with the reports that decreased abundance of Bacteroidetes can contribute to disease pathogenesis in $\operatorname{IBD}(24,25)$. In addition, we also found that the levels of Verrucomicrobiota were reduced in Atg16L1 ${ }^{\mathrm{T} 300 \mathrm{~A} / \mathrm{T} 300 \mathrm{~A}}$ mouse colonic mucosa, and a similar observation has been reported in IBD patients $(26,27)$.

At the family level, the relative abundance of Helicobacteraceae, Ruminococcaceae, and Deferribacteraceae in the $\operatorname{Atg} 16 \mathrm{~L} 1^{\mathrm{T} 300 \mathrm{~A} / \mathrm{T} 300 \mathrm{~A}}$ mice was increased compared with that of the WT mice (Figure 2B). Helicobacteraceae played a pathogenic role in the development of CD in a considerable proportion of children (28, 29), and Ruminococcaceae and Deferribacteraceae were increased in DSS-treated colitis mice (30). Interestingly, the relative abundances of Akkermansiaceae in Atg16L1 $1^{\mathrm{T} 300 \mathrm{~A} / \mathrm{T} 300 \mathrm{~A}}$ mice were decreased dramatically compared with those of WT mice. Akkermansia muciniphila (A. muciniphila), a mucin-degrading bacterium, has been proved associated with healthy mucosa and plays a protective role in regulating intestinal epithelium and mucosal function (31). A. muciniphila reduction has been shown in ulcerative colitis (UC) and Crohn's disease (CD), both in clinically active diseases and during the remission phase. Moreover, it has been reported that $A$. muciniphila can act as a biomarker to predict CD $(31,32)$. Moreover, a study in 2011 demonstrated an inverse correlation between A. muciniphila levels and the severity of acute appendicitis (33).

Venn diagrams are extensively used for the visualization of relationships between different group datasets to illustrate their similarities and differences. At the genus level, Venn diagram analysis indicated that the T300A variant led to reduced microbiota diversity compared with WT control mice (Figure 2C) (86 and 16), suggesting that Atg16L1 T300A polymorphism reduced the mucosa-associated bacterial composition. In addition, Wilcoxon rank-sum test analysis 
A

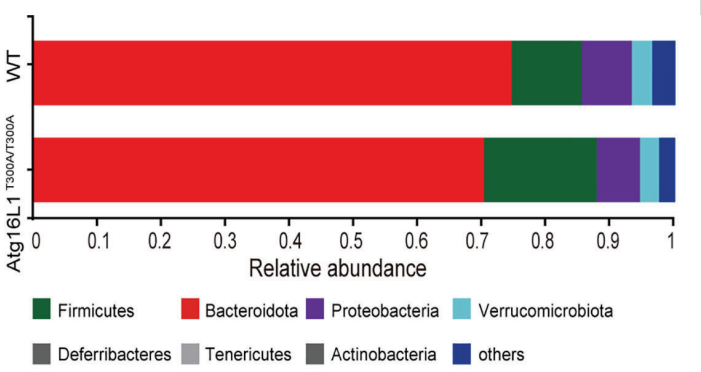

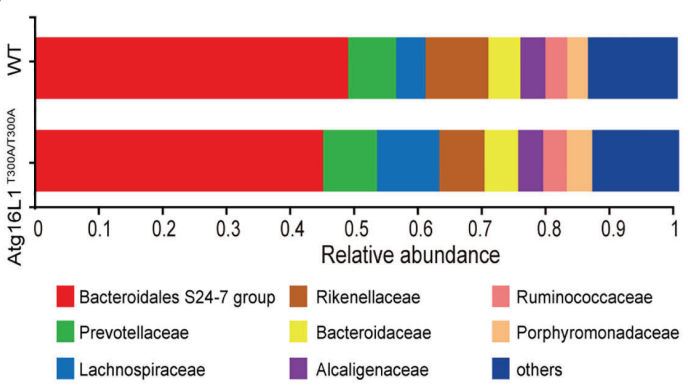

C

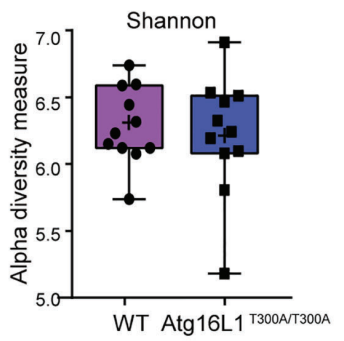

E

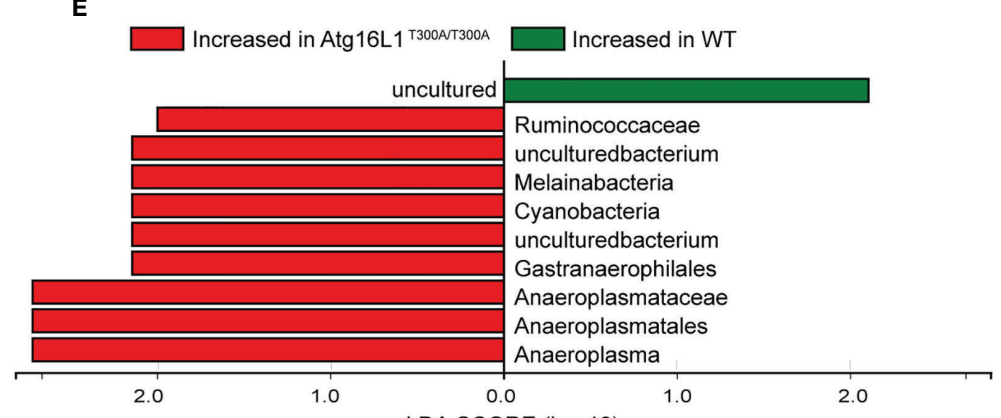

D

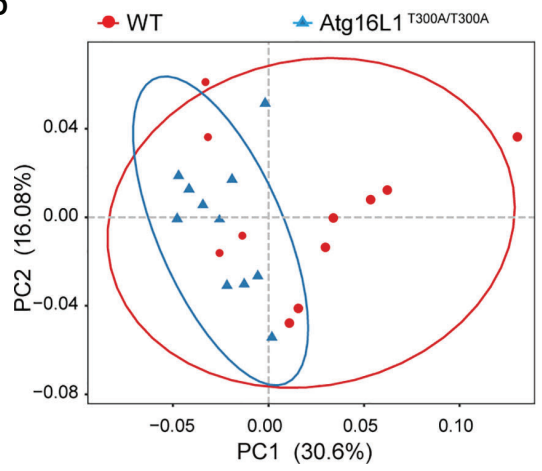

LDA SCORE $(\log 10)$

Ruminococcaceae

uredbacterium

unculturedbacterium

Gastranaerophilales

Anaeroplasmataceae

Anaeroplasmatales

1.0

2.0

FIGURE 1 | Atg16L1T300A mice display a slightly different microbial composition in fecal at a steady state. WT and Atg16L1 ${ }^{\text {T300AT300A }}$ mice were cohoused in a specific-pathogen-free (SPF) facility for 4-5 weeks after weaning at the third week of birth. (WT mice $n=11$ and Atg16L1 $1^{\text {T300AT300A }}$ mice $n=11$ ). Stool samples were collected and analyzed by $16 \mathrm{~S}$ rRNA gene amplicon sequencing. (A, B) The relative abundance of dominant bacteria at phyla (A) and families (B) level microbiota composition determined by $16 \mathrm{~S}$ rRNA gene amplicon sequencing of stool samples from SPF cohoused WT vs. Atg16L1 $1^{\text {T300AT300A }}$ mice at steady state. Colored bars represent the relative abundance of particular taxa averaged in each group. (C) Box-and-whisker plot (boxes show median, whisker denotes minimum to maximum range) of microbiota alpha-diversity within the fecal microbiomes of WT vs. Atg16L1 ${ }^{\text {T300AT } 300 A}$ SPF mouse samples calculated using the Shannon index. (D) PCoA plot of the fecal microbiota composition (unweighted UniFrac distances). (E) Histogram of LDA value distribution identified by LEfSe analysis. Each symbol represents an individual animal (non-parametric test followed by a Mann-Whitney test).

based on genus level found that several taxonomic clades significantly differed between $\operatorname{Atg} 16 \mathrm{~L} 1^{\mathrm{T} 300 \mathrm{~A} / \mathrm{T} 300 \mathrm{~A}}$ mice and those of cohoused WT controls. For instance, the proportions and relative abundance of Akkermansia, Blautia, and norank_o_Clostridia_vadinBB60_group diminished significantly in the colon of $\operatorname{Atg} 16 \mathrm{~L} 1^{\mathrm{T} 300 \mathrm{~A} / \mathrm{T} 300 \mathrm{~A}}$ mice (Figure 2D and Figure S1B), while the opportunistic pathogens such as norank_ f_Lachnospiraceae, norank_f_Ruminococcaceae, Tyzzerella, Mucispirillum, and Lachnospiraceae_FCS020_group significantly increased in $\operatorname{Atg} 16 \mathrm{~L} 1^{\mathrm{T} 300 \mathrm{~A} / \mathrm{T} 300 \mathrm{~A}}$ mice (Figure 2E and Figure S1B), and the changes of the above bacteria were associated with IBD development (34-37).
To gain more insight into the changes of microbiota resident in colon mucus in Atg16L1 $1^{\mathrm{T} 300 \mathrm{~A} / \mathrm{T} 300 \mathrm{~A}}$ mice, we next analyzed the microbiota abundance from the genus to species levels by using the LEfSe method as a visualization tool. We found more than twenty differentially abundant taxonomic clades with an LDA score higher than 2.0 in Atg16L1 ${ }^{\mathrm{T} 300 \mathrm{~A} / \mathrm{T} 300 \mathrm{~A}}$ mice. Many of them were consistent with Wilcoxon rank-sum test analysis (Figure 2F) and had been reported associated with $\operatorname{IBD}$ patients $(26,31)$. These results indicated altered IBD-associated microbiota resident in $\operatorname{Atg} 16 \mathrm{~L} 1^{\mathrm{T} 300 \mathrm{~A} / \mathrm{T} 300 \mathrm{~A}}$ mice even under a steady state.

We next analyzed the microbiota composition in ileum mucosa. We found that the T300A risk allele altered the composition of 


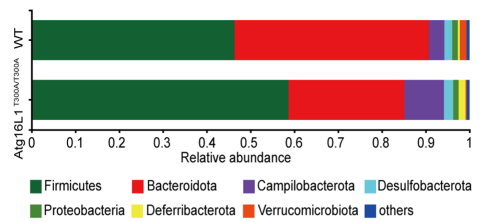

C

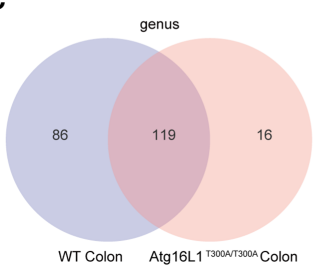

D
B
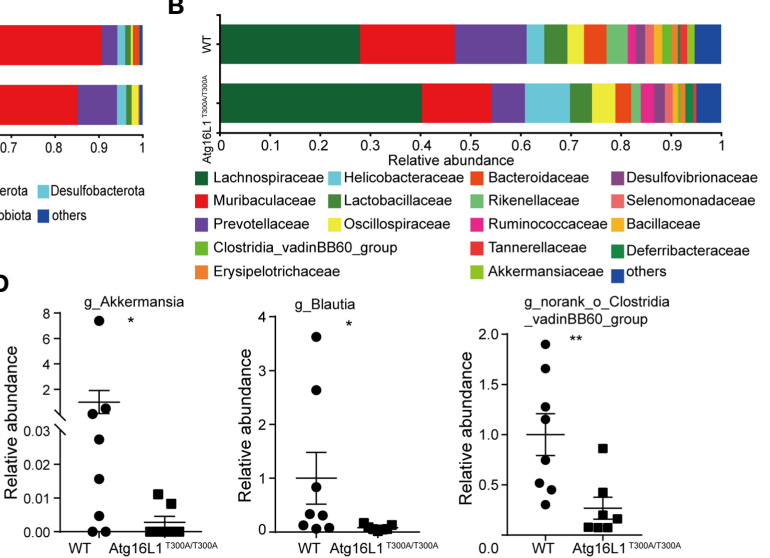
g_norank_o_Clostridi

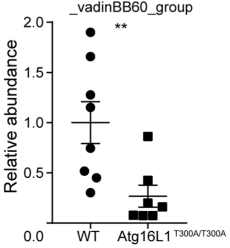

E

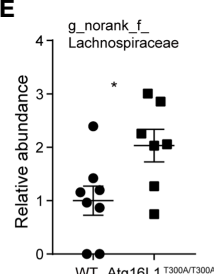
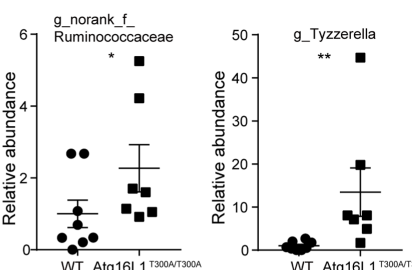

(10
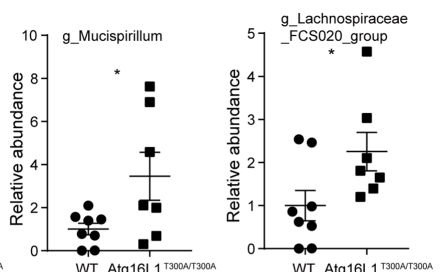

$\mathbf{F}$

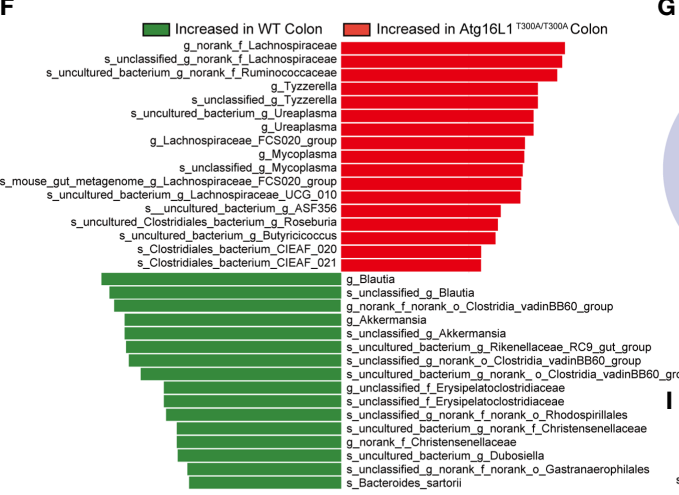

G

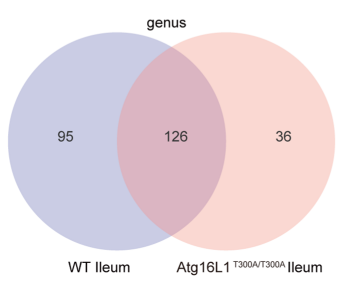

H

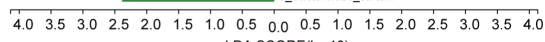
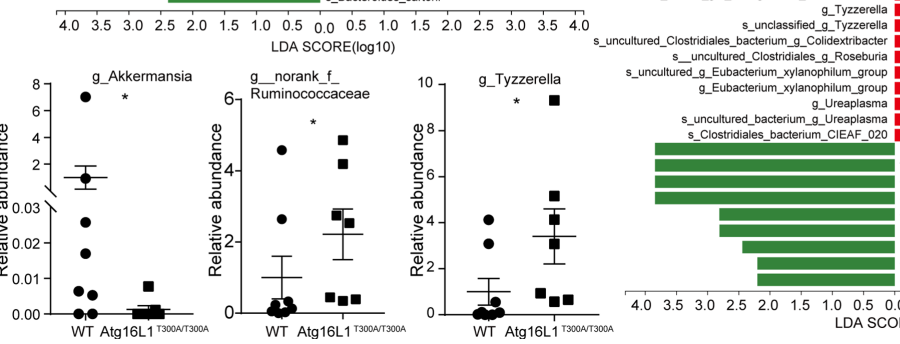

9_Eubacterium_xylanophilum_group
g_Ureaplasma
s_uncultured_bacterium__Ureaplasma
s_Clostridiales bacterium_CIEAF_020

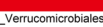

f-Verrucomicrob

9_Akkermansia

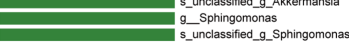

s_unclassified_a_sh

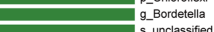

$\begin{array}{lllllllllllllllll}4.0 & 3.5 & 3.0 & 2.5 & 2.0 & 1.5 & 1.0 & 0.5 & 0.0 & 0.5 & 1.0 & 1.5 & 2.0 & 2.5 & 3.0 & 3.5 & 4.0\end{array}$ LDA SCORE (log 10)

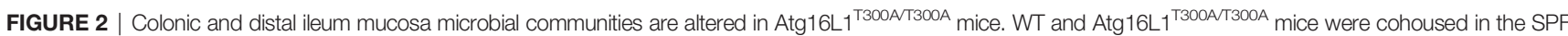

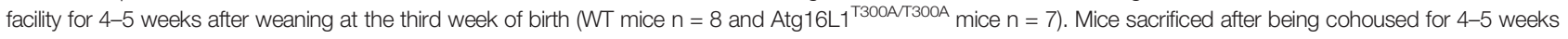
and whole colon and distal ileum excised. DNA was extracted from the colonic mucosa lining, and 16S rRNA gene sequencing was performed to profile bacterial taxa in each group. (A, B) The relative abundance of dominant bacteria at phyla- (A) and family- (B) level microbiota composition in colonic mucosa. Colored bars represent the relative abundance of particular taxa averaged in each group. (C) Venn diagram showing unique and shared genus among the WT and Atg16L $1^{\text {T300AT300A }}$ mouse colon

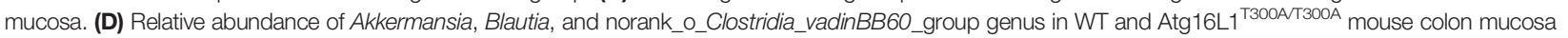
scraping samples. Each dot represents an individual mouse sample. (E) Relative abundance of norank_f_Lachnospiraceae, norank_f_Ruminococcaceae, Tyzzerella, Mucispirillum, and Lachnospiraceae_FCSO20_group genus in WT and Atg16L1 ${ }^{\text {T300A } T 300 A}$ mouse colon mucosa scraping samples. Each dot represents an individual mouse sample. (F) Histogram of LDA value distribution identified by LEfSe analysis of colon mucosa scraping samples. (G) The common and specific genus was shown by the Venn diagram between WT and Atg16L1 ${ }^{T 300 A T 300 A}$ mouse ileal mucosa. (H) Relative abundance of Akkermansia, norank_f_Ruminococcaceae, and Tyzzerella genus in WT and Atg16L1 ${ }^{\text {T300AT300A }}$ mouse ileum mucosa scraping samples. Each dot represents an individual mouse sample. (I) Histogram of LDA value distribution identified by LEfSe analysis of ileum mucosa scraping samples. The relative bacterial abundance was calculated by normalizing each WT and T300A mouse bacterial abundance with the mean value of bacterial abundance of all WT mice. ${ }^{*} \mathrm{p}<0.05,{ }^{* *} \mathrm{p}<0.01$ (non-parametric test followed by a Mann-Whitney test). 
mucosa-associated bacteria in Atg16 $\mathrm{L1}^{\mathrm{T} 300 \mathrm{~A} / \mathrm{T} 300 \mathrm{~A}}$ mice and was similar to what was observed in the colon mucus. A Venn diagram analysis indicated that Atg16L1T300A led to a reduction in the abundance of genus compared with WT mice (95 and 36) (Figure 2G), suggesting that Atg16L1 T300A polymorphism reduced the mucosa-associated bacterial diversity in the ileum as well. Wilcoxon rank-sum test analysis indicated that the proportions and relative abundance of probiotic bacteria Akkermansia decreased dramatically in the ileum, and the relative abundance of opportunistic pathogens Tyzzerella and norank_f_Ruminococcaceae, profoundly overrepresented bacteria in IBD, were also increased in $\operatorname{Atg} 16 \mathrm{L1}^{\mathrm{T} 300 \mathrm{~A} / \mathrm{T} 300 \mathrm{~A}}$ mouse ileum mucosa (Figure 2H and Figure S1C). LEfSe analysis from genus to species further confirmed the finding that the T300A risk allele significantly altered the abundance of bacteria residing in the mucus gel layer of the ileum, and approximately twenty differentially abundant taxonomic clades with LDA score higher than 2.0 in $\operatorname{Atg} 16 \mathrm{~L}^{\mathrm{T} 300 \mathrm{~A} / \mathrm{T} 300 \mathrm{~A}}$ mouse ileum mucosa were found (Figure 2I).

Collectively, these findings indicated that the mucusassociated gut microbiome composition in the ileum and colon of Atg16L1 ${ }^{\mathrm{T} 300 \mathrm{~A} / \mathrm{T} 300 \mathrm{~A}}$ mice displayed an IBD-associated microbe species even under the steady state in our facility.

\section{Atg16L1 ${ }^{\text {T300A/T300A }}$ Mice Exhibit Goblet Cell Morphology Abnormality in the Intestine}

The data above showed that Akkermansia was decreased dramatically in the mucus of $\operatorname{Atg} 16 \mathrm{~L} 1^{\mathrm{T} 300 \mathrm{~A} / \mathrm{T} 300 \mathrm{~A}}$ mice in both colon and ileum mucosa. Akkermansia, as a gramnegative and strictly anaerobic bacterium, tended to widely colonize the nutrient-rich intestinal mucus gel layer (MGL) and was particularly effective in increasing mucus thickness and gut barrier function to maintain the homeostasis of the intestinal microbiota (38). Colonization with Akkermansia has been reported to promote mucosal wound healing $(39,40)$. Its metabolic and mucolytic activity makes Akkermansia a key species in the mucus layer, stimulating beneficial mucosal microbial networks. Because the MGL is composed mainly of mucin (Muc2) secreted by goblet cells, we hypothesized that the decreased Akkermansia composition in the Atg16L1 ${ }^{\mathrm{T} 300 \mathrm{~A} / \mathrm{T} 300 \mathrm{~A}}$ ileum and colon mucosal layer may be correlated with the defect of the mucin secretion (41-43). To test this possibility, we first investigate the morphology of the goblet cell in the colon. Colon sections from Atg16L1 $1^{\mathrm{T} 300 \mathrm{~A} / \mathrm{T} 300 \mathrm{~A}}$ and cohoused WT mice were performed with PAS staining. PAS staining labels highly glycosylated proteins, most notably in goblet cell mucins. We found that Atg16L1 ${ }^{\mathrm{T} 300 \mathrm{~A} / \mathrm{T} 300 \mathrm{~A}}$ mice had larger areas of mucin (Figures 3A, B) and enlarged goblet cells within the surface epithelial cuffs than WT controls (Figure 3C). However, the total number of goblet cells per crypt did not change compared to WT controls (Figure 3D), suggesting that the Atg16L1 T300A variant did not regulate the differentiation of goblet cells in the gut. These results are similar to what was observed in mice with a complete absence of autophagy protein $\operatorname{Atg} 5$ (44).
Similarly, although the total number of goblet cells per crypt was comparable in the ileum between WT and $\operatorname{Atg} 16 \mathrm{~L}^{\mathrm{T} 300 \mathrm{~A} / \mathrm{T} 300 \mathrm{~A}}$ mice (Figures 3E, H), the ileum goblet cells of Atg16 $\mathrm{L1}^{\mathrm{T} 300 \mathrm{~A} / \mathrm{T} 300 \mathrm{~A}}$ mice also contained larger areas of cytoplasmic mucin and an increased number of enlarged goblet cells (Figures 3F, G), which is in contrast to the previous report that the enlarged goblet cell number in the small intestinal was unchanged (45). The discrepancy between the two studies was probably due to the difference in the microbiota of the two-mouse facility.

\section{Secretion Capacity of Goblet Cells Was Attenuated in Atg16 $1^{\mathrm{T} 300 \mathrm{~A} / \mathrm{T} 300 \mathrm{~A}}$ Mice}

Goblet cells are a secretory lineage that specializes in mucus production. Goblet cells secrete mucus, which forms a layer that overlays the epithelium and forms an important barrier to intestinal microbes (46). Although it has been reported that Atg16L1 $1^{\mathrm{T} 300 \mathrm{~A} / \mathrm{T} 300 \mathrm{~A}}$ results in enlarged goblet cells within the surface epithelial cuffs (45), the consequence of enlarged goblet cells in Atg16L1 ${ }^{\mathrm{T} 300 \mathrm{~A} / \mathrm{T} 300 \mathrm{~A}}$ mice has never been studied. Intestinal mucus is composed of multiple highly glycosylated proteins called mucins. Mucins are stored in secretory granules; constitutive secretion occurs by fusion of individual mucin granules with the apical plasma membrane (47). Mucin granules can accumulate within the goblet cell cytoplasm leading to increased size, which can be secondary to either increased mucin production or diminished secretion. To examine whether the enlarged goblet cell in Atg16L1 $1^{\mathrm{T} 300 \mathrm{~A} / \mathrm{T} 300 \mathrm{~A}}$ mice was due to impaired secretion, we first used transmission electron microscopy to visualize the theca of goblet cells, which is normally packed with mucin granules. We found that in WT mice, once the theca-containing mucin granules reach the apical surface of the intestinal epithelium, they fuse with the epithelium, releasing the stored mucins and associated proteins into the intestinal lumen. In contrast, the goblet cell from Atg16L1 ${ }^{\mathrm{T} 300 \mathrm{~A} / \mathrm{T} 300 \mathrm{~A}}$ mice was featured with an increased accumulation of intracellular mucin granules and an apparent inability of these granules to fuse with the apical surface of the intestinal epithelium (Figure 4A), which resulted in a deficiency of mucin release. To further confirm the defect of mucin secretion in Atg16L1 $1^{\mathrm{T} 300 \mathrm{~A} / \mathrm{T} 300 \mathrm{~A}}$ mice, we detected mucin in the lumen of the intestine by whole-mount staining. To this end, colons obtained from cohoused WT and Atg16L1 $1^{\mathrm{T} 300 \mathrm{~A} / \mathrm{T} 300 \mathrm{~A}}$ mice were collected and opened longitudinally after the adipose tissues were stripped off. 2-3-cm equal intestine sections were fixed and stained with fluorescein isothiocyanate-labeled $\mathrm{H}$. pomatia lectin at room temperature, after which the images were taken immediately above the colon mucosal surface. We found that mucus secreted into the colon lumen was reduced in $\operatorname{Atg} 16 \mathrm{~L} 1^{\mathrm{T} 300 \mathrm{~A} / \mathrm{T} 300 \mathrm{~A}}$ mice compared with that of cohoused WT controls (Figure 4B). These results indicate that $\operatorname{Atg} 16 \mathrm{~L} 1^{\mathrm{T} 300 \mathrm{~A} / \mathrm{T} 300 \mathrm{~A}}$ goblet cells had a defect in granule exocytosis and a lack of intact mucus layer.

The diminished secretion of mucin in the lumen of the Atg16L1 $1^{\text {T300A/T300A }}$ mice could be due to impaired mucin gene expression. Muc2 is the predominant mucin secreted by goblet cells, so we analyzed Muc2 expression in the colon epithelium from cohoused WT and Atg16L1 $1^{\mathrm{T} 300 \mathrm{~A} / \mathrm{T} 300 \mathrm{~A}}$ mice by real-time 
A

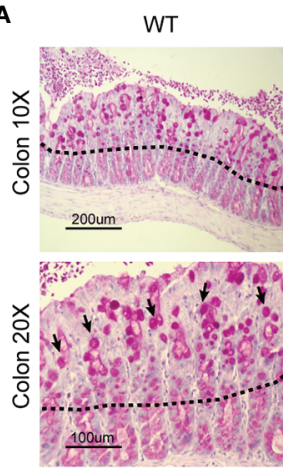

E

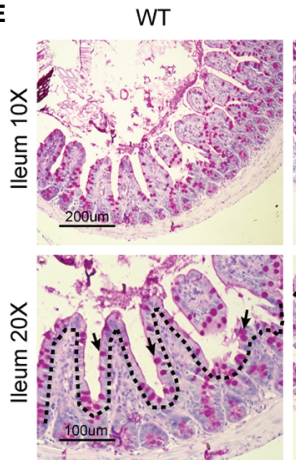

Atg16L1 T300AT300A

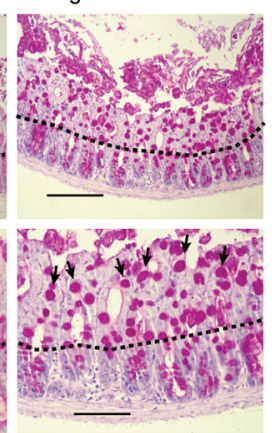

Atg16L 1 T300AT $300 \mathrm{~A}$

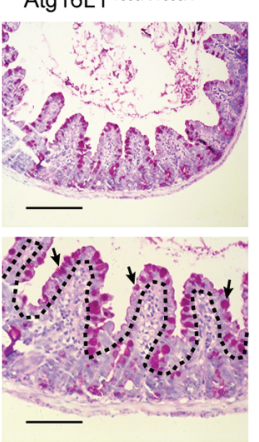

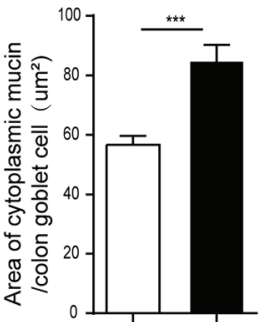

WT Atg16L1 ${ }^{\text {T300AT300A }}$
C

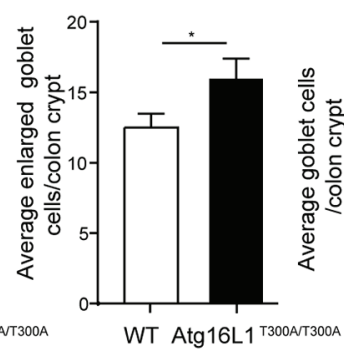

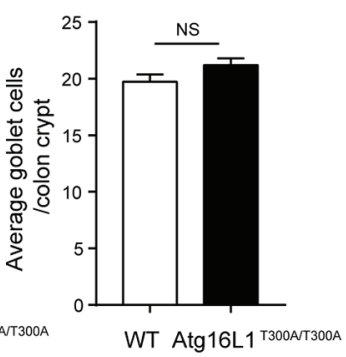

G

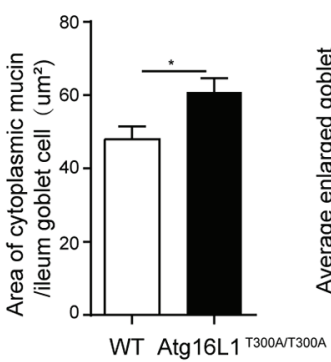

H

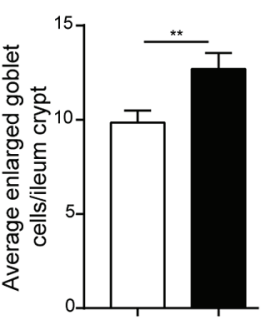

WT Atg16L1 ${ }^{\text {T300AT } 300 \text { A }}$

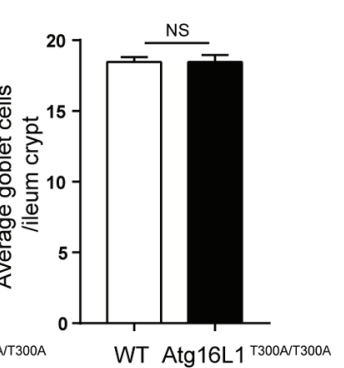

FIGURE 3 | Atg16L1 ${ }^{\text {T300AT300A }}$ mice display morphological abnormalities in their Goblet cells. (A) PAS-stained colonic sections of cohoused WT and Atg16L1 ${ }^{\text {T300AT300A }}$ mice. Hematoxylin is in blue. Black dotted lines outline the surface epithelium. Arrows indicate surface goblet cells (scale bars: down, $100 \mu \mathrm{m}$ and upper, $200 \mu \mathrm{m}$ ). (B) Quantification of average mucin area/colon goblet cells, and (C) average number of enlarged goblet cells in the upper crypt region of cohoused WT and Atg16L1 ${ }^{\text {T300AT300A }}$ mouse colon. (D) Quantification of the total number of goblet cells per crypt in the colon of WT and Atg16L $1^{\text {T300AT300A }}$ mice $(n=6-8$ mice/group from 3 independent experiments; 50 goblet cells measured/mouse). This analysis was performed on upper crypt goblet cells [above the upper dashed line in (A)]. (E) PASstained ileum sections of cohoused WT and Atg16L1 $1^{\text {T300AT } 300 A}$ mice. Hematoxylin is in blue. Black dotted lines outline the surface epithelium. Arrows indicate surface goblet cells (scale bars: down, $100 \mu \mathrm{m}$ and upper, $200 \mu \mathrm{m}$ ). (F) Quantification of the average area of cytoplasmic mucin/lieum goblet cells in the upper crypt region of WT and Atg16L1 ${ }^{\text {T300ATTOOA }}$ mouse ileum. (G) Quantification of the average number of enlarged goblet cells in the upper crypt region and (H) the average total number of goblet cells per crypt in the ileum of WT and Atg16L1 ${ }^{T 300 A T 300 A}$ mice ( $n=6-8$ mice/group from 3 independent experiments; 50 goblet cells measured/mouse). This analysis was performed on upper crypt goblet cells [above the upper dashed line in (F)]. Data are expressed as mean and s.e.m. ${ }^{*} p<0.05,{ }^{* *} p<0.01,{ }^{* * *} p<0.001$, NS, not significant (non-parametric test followed by a Mann-Whitney test).

PCR. We found no difference in the expression of Muc2 in cohoused WT and Atg16L1 ${ }^{\mathrm{T} 300 \mathrm{~A} / \mathrm{T} 300 \mathrm{~A}}$ mice (Figure 4C), supporting the conclusion that the reduced mucin observed in the colon was not due to the gene expression but the deficiency of secretion.

The MGL lining the colon is integral to preventing bacterial invasion and maintaining intestinal homeostasis in health and disease. MGL defects allow bacteria to contact the colonic surface directly and are commonly observed in IBD (48). Having observed defected mucin secretion of goblet cells in $\operatorname{Atg} 16 \mathrm{~L} 1^{\mathrm{T} 300 \mathrm{~A} / \mathrm{T} 300 \mathrm{~A}}$ mice, we next determined whether the reduced secretion of mucin could impair the homeostasis of mucus lining. We examined the spatial distance between mucosal surfaces and the luminal contents by fluorescence in situ hybridization (FISH) assay with a universal 16S ribosomal RNA (rRNA) gene probe. We found that the spatial distance of mucosal surfaces and the luminal contents were approximately $\sim 45 \mu \mathrm{m}$ (from the villus tip) in WT mice (Figures 4D, I). In contrast, a marked decrease in spatial distance between mucosal surfaces and the luminal contents was observed in Atg16L1 $1^{\mathrm{T} 300 \mathrm{~A} / \mathrm{T} 300 \mathrm{~A}}$ mice $(\sim 25 \mu \mathrm{m})$. We also examined mucin secretion in the ileum as above. The results showed decreased mucus secretion in the ileum lumen of $\operatorname{Atg} 16 \mathrm{~L} 1^{\mathrm{T} 300 \mathrm{~A} / \mathrm{T} 300 \mathrm{~A}}$ mice compared with WT controls (Figure 4E).

Collectively, these findings indicate that Atg16L1T300A polymorphism regulated the secretion capacity of intestinal goblet cells, which may contribute to microbiota dysbiosis in $\operatorname{Atg} 16 \mathrm{~L} 1^{\mathrm{T} 300 \mathrm{~A} / \mathrm{T} 300 \mathrm{~A}}$ mice.

\section{The Impaired Function of Atg16L1 T300A Goblet Cell Is Autophagy-Dependent}

To further investigate the mechanism by which Atg16L1T300A polymorphism regulates goblet cell secretion, we next investigated whether the impaired secretion function of Atg16L1 T300A goblet cells is due to the defective autophagic process which is required for proper secretion of mucus granules. We crossed Atg16 $\mathrm{L}^{\mathrm{f} / \mathrm{f}}$ mice with ERT2Cre mice to generate $\operatorname{Atg} 16 \mathrm{~L}^{\mathrm{f} / \mathrm{f}} \& \mathrm{ERT} 2 \mathrm{Cre}^{+}$mice. Tamoxifen was orally administrated to Atg16 $\mathrm{L1}^{\mathrm{f} / \mathrm{f}} \& \mathrm{ERT} 2 \mathrm{Cre}^{+}$ 
A

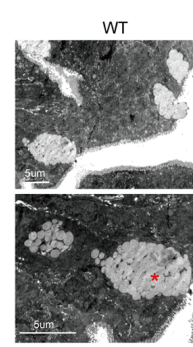

D
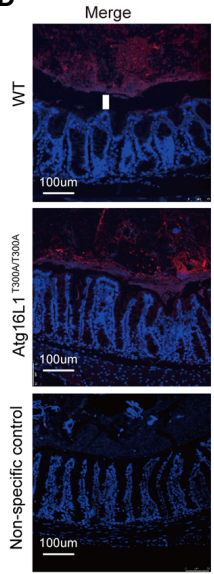

H

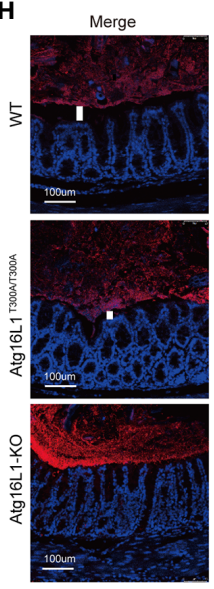

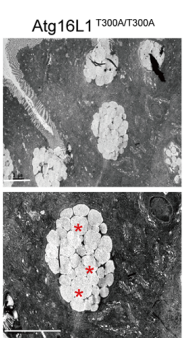

EUB338-Probe
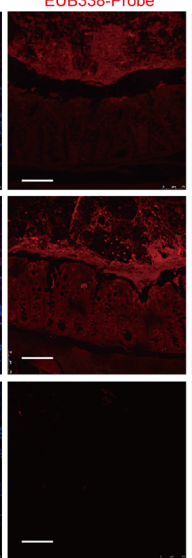

EUB338-Probe
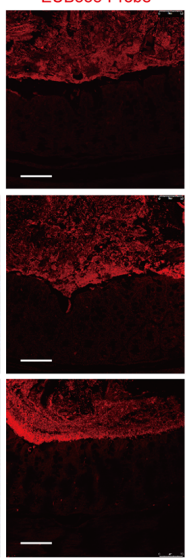

B

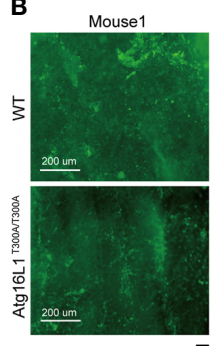

DAPI

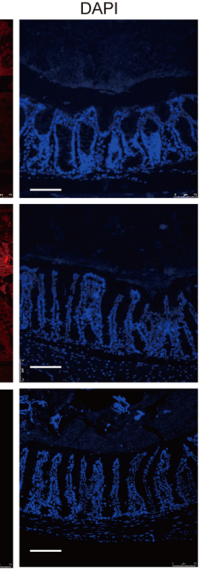

E
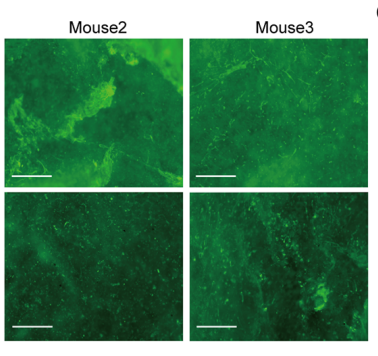

C
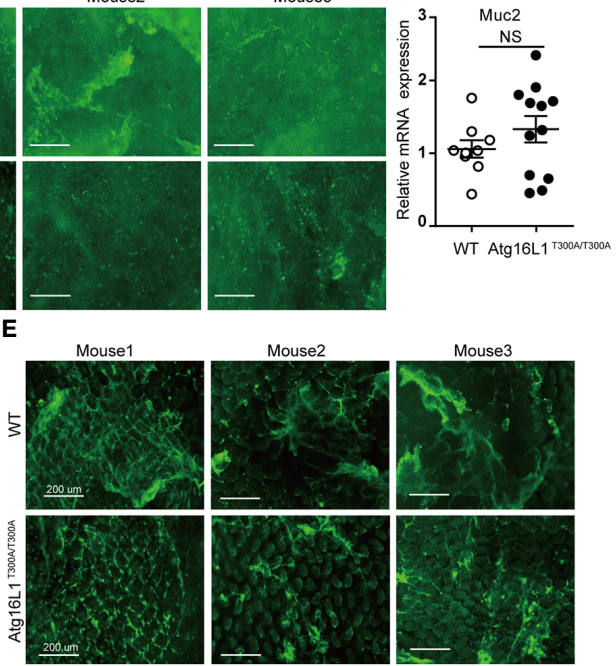

Mouse3

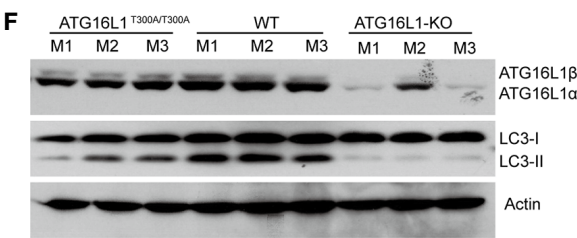

G

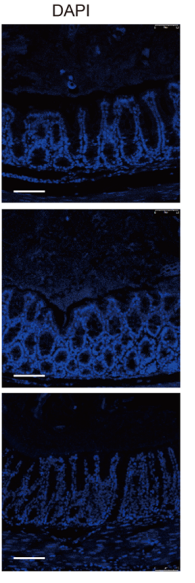

$\operatorname{Atg} 16 \mathrm{~L} 1^{\text {T300AT } 3000}$

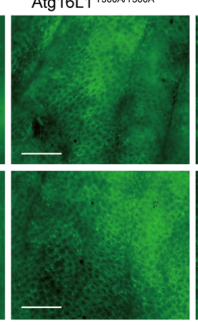

Atg16L1-KO

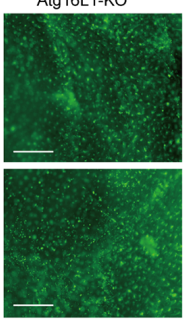

I

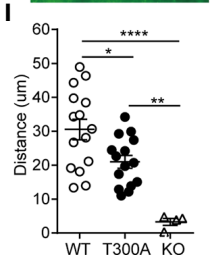

FIGURE 4 | Impaired function of mucin secretion in Atg16L1 ${ }^{\text {T300ATT300A }}$ goblet cells is autophagy-dependent. Isolated colon or distal ileum tissues from cohoused WT and Atg16L1 ${ }^{\text {T300A } T 300 A}$ mice stained with Helix pomatia lectin for mucus secretion by whole-mount staining, and microbiota localization in the colon was detected by FISH staining. $\mathrm{n}=6-8$ mice/group. (A) Representative transmission electron microscopy images were taken from intestine sections of cohoused WT and Atg16L1 ${ }^{\text {T300AT300A }}$ mice. Red asterisks indicate enlarged granules; $n=5$ mice per genotypes. Scale bars, $5 \mu \mathrm{m}$. (B) Representative whole-mount images of tissues

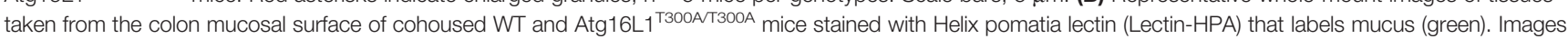
are representative of at least three independent experiments. Scale bars, $200 \mu \mathrm{m}$. (C) Quantitative real-time PCR analysis of mucus (Muc2) mRNA of cohoused WT and Atg16L1 ${ }^{\text {T300ATT300A }}$ mouse colonic epithelium; results are presented relative to those of wild-type mice. (D) Visualization of microbiota localization relative to the intestinal mucosa of the colon surface by FISH. Sections were hybridized with the EUB338 probe recognizing the 16S rRNA genes of all bacteria (red) or nonEUB338 as a non-specific control and counterstained with DAPI (blue). Scale bar: $100 \mu \mathrm{m}$. (E) Representative whole-mount images taken from the ileum mucosal

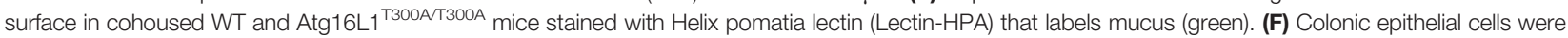
isolated from the colon of cohoused WT, Atg16L1 ${ }^{T 300 A T 300 A}$, and Atg16L1-KO mice, and Western blot analysis was used to detect Atg16L1 and LC3 changes from whole-cell lysates. Actin was used as loading control. $n=3$ mice/group. (G) Representative whole-mount images of tissues taken from the colon mucosal surface of cohoused wild-type, Atg16L1 ${ }^{\text {T300ATT300A }}$, and Atg16L-KO mice stained with Helix pomatia lectin (Lectin-HPA) that labels mucus (green). (H) Visualization of microbiota localization relative to the intestinal mucosal of the colon surface by FISH. Sections were hybridized with the EUB338 probe recognizing the $16 \mathrm{~S}$ rRNA genes of all bacteria (red) and counterstained with DAPI (blue). Scale bar: $100 \mu \mathrm{m}$. The white column indicates the distance between the apical surface of the epithelium and the luminal contents. (I) Quantification of the distance of separating villi from microbiota in (D, H). Data are from at least three independent experiments. Each symbol represents an individual animal. ${ }^{\star} \mathrm{p}<0.05,{ }^{\star \star} \mathrm{p}<0.01,{ }^{\star \star \star \star} \mathrm{p}<0.0001$. NS, not significant (non-parametric test followed by a Mann-Whitney test; one/two-way ANOVA analysis followed by a Tukey/Bonferroni post hoc test for three-group analysis). 
mice to generate Atg16L1-KO mice. Colon epithelial cells collected from WT, Atg16L1 ${ }^{\mathrm{T} 300 \mathrm{~A} / \mathrm{T} 300 \mathrm{~A}}$, and Atg16L1-KO mice were lysed and immunoblotted with the anti-Atg16L1 antibody; we found that Atg16L1 expression was comparable between WT and $\operatorname{Atg} 16 \mathrm{~L} 1^{\mathrm{T} 300 \mathrm{~A} / \mathrm{T} 300 \mathrm{~A}}$ mice, but almost completely lost in Atg16L1-KO mice (Figure 4F). These results indicated that Atg16L1 T300A mutation did not influence the Atg16L1 expression and tamoxifen administration activates ERT2Cre and deleted Atg16L1 expression. We next studied autophagy induction in the intestine epithelial cell (mainly containing goblet cell). The colon epithelial cell was collected from WT, Atg16 L1 ${ }^{\mathrm{T} 300 \mathrm{~A} / \mathrm{T} 300 \mathrm{~A}}$, and Atg16L1 KO mice as above, and autophagy induction was detected by LC3 conversion. We observed that LC3II conversion was impaired significantly in intestinal epithelial cells of Atg16L1 $1^{\text {T300A/T300A }}$ mice compared with those of cohoused WT mice, indicating that autophagy was impaired in Atg16 L1 $1^{\mathrm{T} 300 \mathrm{~A} / \mathrm{T} 300 \mathrm{~A}}$ intestinal epithelial cells; LC3II was almost completely lost in epithelial cells of Atg16L1-KO mice (Figure 4F).

To detect the effect of autophagy on mucus secretion directly, we performed whole-mount staining in both Atg16 $\mathrm{L}^{\mathrm{T} 300 \mathrm{~A} / \mathrm{T} 300 \mathrm{~A}}$ and Atg16L1-KO mice as above, and the results showed that Atg16L1 KO mice had more drastic effects on mucin secretion; mucus secreted was almost completely lost in Atg16L1-KO mice compared with that of WT controls (Figure 4G). These findings suggested that impaired mucin secretion in $\operatorname{Atg} 16 \mathrm{L1}^{\mathrm{T} 300 \mathrm{~A} / \mathrm{T} 300 \mathrm{~A}}$ mice is autophagy-dependent, which is consistent with the previous report that autophagy was required for mucin granule exocytosis of goblet cells (44). Finally, we performed FISH staining with the colon of WT, Atg16L1 $1^{\mathrm{T} 300 \mathrm{~A} / \mathrm{T} 300 \mathrm{~A}}$, and Atg16L1-KO mice to examine the spatial distance between mucosal surfaces and the luminal contents. The result showed that the distance between the apical surface of the epithelium and the luminal contents in Atg16L1-KO mice reduced dramatically compared with that of Atg16L1 $1^{\mathrm{T} 300 \mathrm{~A} / \mathrm{T} 300 \mathrm{~A}}$ and WT mice, and commensal bacteria were directly attached to the epithelia of Atg16L1-KO mice (Figures 4H, I). These findings indicated that reduced mucin secretion of goblet cells in Atg16L1 T300A mice is autophagy-dependent.

\section{Atg16L1 ${ }^{\text {T300A/T300A }}$ Mice Exhibit More Severe Inflammation in DSS- Induced Colitis}

Dextran sodium sulfate (DSS)-induced colitis is a model commonly used to study host-microbial interactions characterized by a defect in mucus gel layer and microbiota alterations (17). In addition, the administration of DSS disrupts the intestinal barrier and effectively mimics the clinical and histological features of IBD patients (49). Therefore, we next investigated whether $\operatorname{Atg} 16 \mathrm{~L} 1^{\mathrm{T} 300 \mathrm{~A} / \mathrm{T} 300 \mathrm{~A}}$ mice will be more sensitive to DSS-induced colitis. Accordingly, WT and $\operatorname{Atg} 16 \mathrm{~L} 1^{\mathrm{T} 300 \mathrm{~A} / \mathrm{T} 300 \mathrm{~A}}$ mice were administrated with $1.5 \%$ DSS in drinking water for 7 days followed by 3 days of regular drinking water, and then the extent of colitis was evaluated. We observed that the weight loss in Atg16L1 ${ }^{\mathrm{T} 300 \mathrm{~A} / \mathrm{T} 300 \mathrm{~A}}$ mice was comparable with WT mice (Figure 5A). However, the colon length of $\operatorname{Atg} 16 \mathrm{L1} 1^{\mathrm{T} 300 \mathrm{~A} / \mathrm{T} 300 \mathrm{~A}}$ mice was shorter than that of WT mice
(Figures 5B, C). In addition, the colon section was obtained and $\mathrm{H} \& \mathrm{E}$ staining was performed. We found that Atg16L1 ${ }^{\mathrm{T} 300 \mathrm{~A} / \mathrm{T} 300 \mathrm{~A}}$ mice exhibited more intense inflammation in the colon section compared than did WT mice, as indicated by blinded assessment of histopathologic scores (Figures 5D, E). Overall, our data indicated that the presence of Atg16L1 T300A resulted in defects in mucin granule exocytosis and impaired mucus layer formation that altered the microbial community in Atg16L1 ${ }^{\mathrm{T} 300 \mathrm{~A} / \mathrm{T} 300 \mathrm{~A}}$ mice. Because there are many other defects in $\operatorname{Atg} 16 \mathrm{~L} 1^{\mathrm{T} 300 \mathrm{~A} / \mathrm{T} 300 \mathrm{~A}}$ mice, the dysbiosis observed in Atg16L1 $1^{\text {T300A/T300A }}$ mice is probably one of the important factors that contributed to the Atg16L1 $1^{\mathrm{T} 300 \mathrm{~A} / \mathrm{T} 300 \mathrm{~A}}$ variant's susceptibility to Crohn's disease.

\section{DISCUSSION}

The role of the gut microbiota in IBD pathogenesis is well established, but whether genetic risk loci directly affect specific gut microbial population frequency is not known. Here we showed the presence of the CD risk allele Atg16L1 T300A in mice regulated gut microbiota. Atg16L1 $1^{\mathrm{T} 300 \mathrm{~A} / \mathrm{T} 300 \mathrm{~A}}$ mouse intestine mucus displayed an IBD-associated species even under a steady state, which may be one of the important factors that lead to the Atg16L1 T300A carriers being more sensitive to IBD. Mechanically, diminished mucin secretion of Atg16L1 $1^{\mathrm{T} 300 \mathrm{~A} / \mathrm{T} 300 \mathrm{~A}}$ goblet cell resulted in microbiota dysbiosis in Atg16L1 ${ }^{\mathrm{T} 300 \mathrm{~A} / \mathrm{T} 300 \mathrm{~A}}$ mice.

To derive a comprehensive definition of microbial dysbiosis relevant to $I B D$, we analyzed the microbiome from the feces and mucus of the gastrointestinal tract and found that the diversity of bacteria is not uniformly distributed between WT and Atg16L1 $1^{\mathrm{T} 300 \mathrm{~A} / \mathrm{T} 300 \mathrm{~A}}$ mice. For example, Ruminococcaceae were increased in Atg16L1 ${ }^{\mathrm{T} 300 \mathrm{~A} / \mathrm{T} 300 \mathrm{~A}}$ mice in both feces and mucosa, but Tyzzerella and Mucispirillum were increased and Akkermansia was reduced only in the intestinal mucosa of $\operatorname{Atg} 16 \mathrm{~L} 1^{\mathrm{T} 300 \mathrm{~A} / \mathrm{T} 300 \mathrm{~A}}$ mice. Our results here support an understanding of the gastrointestinal regions as microenvironments where the properties of each environment drive the taxonomic composition (50).

The homeostasis of the gut microbiota is essential for maintaining intestinal health, and clear evidence of microbial dysbiosis has been shown in patients with $\operatorname{IBD}(51,52)$. Consistent with previous reports (19), our data showed that Atg16L1 $1^{\mathrm{T} 300 \mathrm{~A} / \mathrm{T} 300 \mathrm{~A}}$ mice displayed an altered gut microbial composition at a steady state. More specifically, Ruminococcaceae were enriched in CD patients of small intestine mucosa and often co-occurring with increased disease activity $(53,54)$, which may also explain that the Atg16L1 T300A variant confers increased risk for the development of Crohn's disease.

Akkermansia, as a mucin-degrading bacteria (38), could continuously reshape and refresh the mucus layer, thereby creating a healthy environment for epithelial cells and maintaining the integrity of the intestinal barrier (43). In vitro, Reunanen et al. (26) found that Akkermansia could strengthen the intestinal epithelial integrity and fortify a destroyed gut 
A
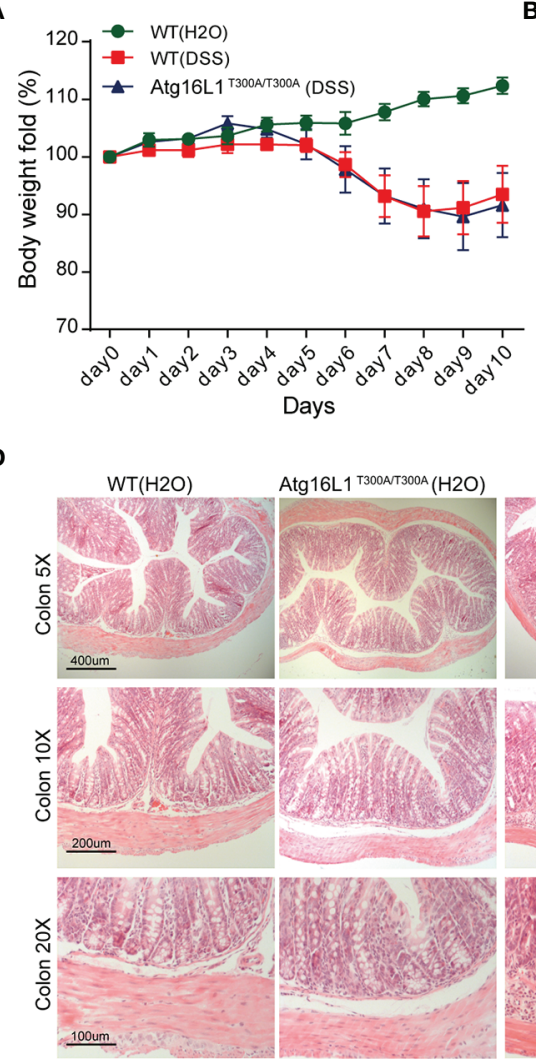

B

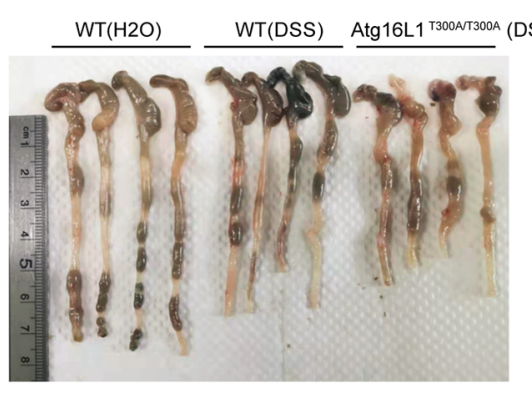

C

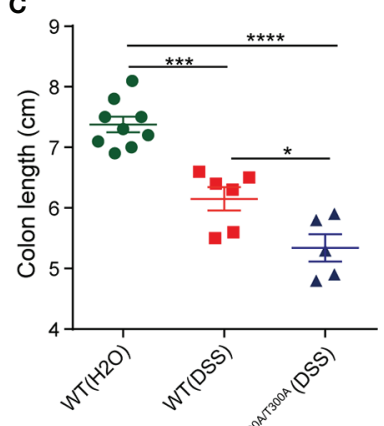

$E$
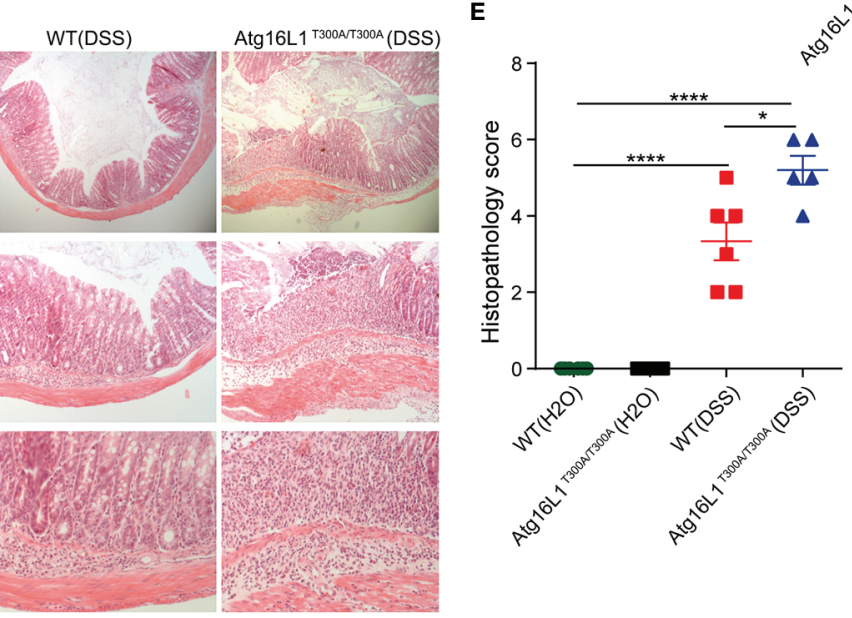

FIGURE 5 | Atg16L1 ${ }^{\text {T300ATT300A }}$ mice exhibit more severe inflammation in DSS-induced colitis. (A) Weight loss of WT mice with drinking water $(n=9,3$ male and 6

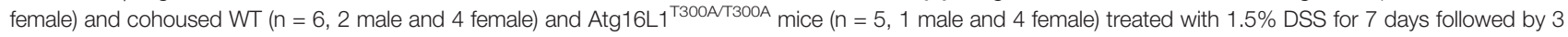
days of regular drinking water. (B, C) Gross pathology of colons on day 10 post 1.5\% DSS. (D) Representative H\&E staining of distal colon sections obtained from

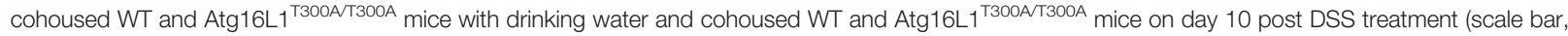
represents $400 \mu \mathrm{m}$; images acquired at 5x; represents $200 \mu \mathrm{m}$; images acquired at 10x; represents $100 \mu \mathrm{m}$; images acquired at 20x). (E) Histological analysis of distal colon harvested at day 10 post-DSS provided by a pathologist blinded to the groups and the study. Results representative of at least 3 independently performed experiments and displayed as mean \pm SEM. ${ }^{\star} p<0.05$; ${ }^{\star \star \star} \mathrm{p}<0.001 ;{ }^{\star \star \star \star} \mathrm{p}<0.0001$ (non-parametric test followed by a Mann-Whitney test; one/two-way ANOVA analysis followed by a Tukey/Bonferroni post hoc test for three group analysis).

barrier. Our results showed that Akkermansia was reduced in both the colon and distal ileum mucosa of the Atg16 $\mathrm{L}^{\mathrm{T} 300 \mathrm{~A} / \mathrm{T} 300 \mathrm{~A}}$ mice, which was consistent with the reports showing that Akkermansia had been decreased in ulcerative colitis and Crohn's disease patients than in healthy individuals $(5,31)$. In addition, another mucus-dwelling bacterium, Mucispirillum schaedleri, increased in both the colon and distal ileum mucosa of the Atg16L1 ${ }^{\mathrm{T} 300 \mathrm{~A} / \mathrm{T} 300 \mathrm{~A}}$ mice, was also reported by Caruso et al., which can trigger $\mathrm{Nod}^{-1-} \& \mathrm{Cybb}^{-1-}$ (double-KO) mice developing spontaneous colitis (35). These results suggest that both Akkermansia and Mucispirillum may play a role in triggering colitis in T300A genetic susceptibility. Furthermore, there is evidence that mucus-consuming bacteria with increased prevalence in IBD patients are also better mucus utilizers in vitro (21), indicating an important role in mucus utilization, mucosal proximity, and disease.

Atg16L1 T300A SNP has multiple effects on the organism. Our results show that goblet cell dysfunction in Atg16L1 $1^{\mathrm{T} 300 \mathrm{~A} / \mathrm{T} 300 \mathrm{~A}}$ mice resulted in intestinal microbiota disorder. In fact, the barrier integrity associated with defects in Paneth cell antimicrobial peptide secretion was also reduced in Atg16L1 hypomorphic mice (9) and Atg16 $1^{\mathrm{T} 300 \mathrm{~A} / \mathrm{T} 300 \mathrm{~A}}$ mice (55). Furthermore, increased production of inflammatory cytokines by Atg16L1-deficient innate immune cells in response to infiltrating bacteria (56) can activate an adaptive immune response to the gut microbiota. Therefore, the occurrence of the T300A variant affecting IBD is caused by a variety of factors, and what is the nature of the co-occurrence relationships between these factors needs to be further studied.

IBD symptoms can vary in nature and severity as well as disease location. While some patients will respond to treatment, others will not, suggesting that subtypes of the disease may be dependent on many factors such as genetics, immunity, and the microbiota. Our study revealed that the risk allele Atg16L1 T300A, an SNP associated with an increased risk of CD, contributes to dysbiosis in mice, which was due to the dysfunction of goblet cells. These data shed light on the etiology of $\mathrm{CD}$ and provided a new perspective for the individualized treatment of IBD. Further clinical studies in humans with IBD need to be investigated. 


\section{DATA AVAILABILITY STATEMENT}

The datasets presented in this study can be found in online repositories. The names of the repository/repositories and accession number(s) can be found in the following: https:// www.ncbi.nlm.nih.gov/, PRJNA735432; PRJNA735442.

\section{ETHICS STATEMENT}

The animal study was reviewed and approved by the Research Ethics Committee of the Institute of Microbiology, Chinese Academy of Sciences (IMCAS).

\section{AUTHOR CONTRIBUTIONS}

HL, PG, BJ, and NL performed the experiments. HL, PG, and FZ designed the study. HL, PG, and FZ analyzed the data. BZ provided expertise and reagents. PG and FZ supervised the study. HL, PG, and FZ wrote the manuscript. All authors contributed to the article and approved the submitted version.

\section{REFERENCES}

1. Sartor RB. Microbial Influences in Inflammatory Bowel Diseases. Gastroenterology (2008) 134(2):577-94. doi: 10.1053/j.gastro.2007.11.059

2. Sun J, Kato I. Gut Microbiota, Inflammation and Colorectal Cancer. Genes Dis (2016) 3(2):130-43. doi: 10.1016/j.gendis.2016.03.004

3. Kaser A, Zeissig S, Blumberg RS. Inflammatory Bowel Disease. Annu Rev Immunol (2010) 28:573-621. doi: 10.1146/annurev-immunol-030409-101225

4. Kostic AD, Xavier RJ, Gevers D. The Microbiome in Inflammatory Bowel Disease: Current Status and the Future Ahead. Gastroenterology (2014) 146 (6):1489-99. doi: 10.1053/j.gastro.2014.02.009

5. Pittayanon R, Lau JT, Leontiadis GI, Tse F, Yuan Y, Surette M, et al. Differences in Gut Microbiota in Patients With vs Without Inflammatory Bowel Diseases: A Systematic Review. Gastroenterology (2020) 158(4):93046.e1. doi: 10.1053/j.gastro.2019.11.294

6. Ni J, Wu GD, Albenberg L, Tomov VT. Gut Microbiota and IBD: Causation or Correlation? Nat Rev Gastroenterol Hepatol (2017) 14(10):573-84. doi: 10.1038/nrgastro.2017.88

7. Lee JC, Biasci D, Roberts R, Gearry RB, Mansfield JC, Ahmad T, et al. Genome-Wide Association Study Identifies Distinct Genetic Contributions to Prognosis and Susceptibility in Crohn's Disease. Nat Genet (2017) 49(2):2628. doi: 10.1038/ng.3755

8. Hampe J, Franke A, Rosenstiel P, Till A, Teuber M, Huse K, et al. A Genome-Wide Association Scan of Nonsynonymous SNPs Identifies a Susceptibility Variant for Crohn Disease in ATG16L1. Nat Genet (2007) 39(2):207-11. doi: 10.1038/ng1954

9. Cadwell K, Liu JY, Brown SL, Miyoshi H, Loh J, Lennerz JK, et al. A Key Role for Autophagy and the Autophagy Gene Atg1611 in Mouse and Human Intestinal Paneth Cells. Nature (2008) 456(7219):259-63. doi: 10.1038/nature07416

10. Gao P, Liu H, Huang H, Zhang Q, Strober W, Zhang F. The Inflammatory Bowel Disease-Associated Autophagy Gene Atg16L1T300A Acts as a Dominant Negative Variant in Mice. J Immunol (2017) 198(6):2457-67. doi: 10.4049/jimmunol.1502652

11. Murthy A, Li Y, Peng I, Reichelt M, Katakam AK, Noubade R, et al. A Crohn's Disease Variant in Atg16l1 Enhances Its Degradation by Caspase 3. Nature (2014) 506(7489):456-62. doi: 10.1038/nature13044

12. Bel S, Pendse M, Wang Y, Li Y, Ruhn KA, Hassell B, et al. Paneth Cells Secrete Lysozyme via Secretory Autophagy During Bacterial Infection of the Intestine. Science (2017) 357(6355):1047-52. doi: 10.1126/science.aal4677

\section{FUNDING}

This work was supported by the National Natural Science Foundation of China grants (31870880 and 31470861 to FZ).

\section{ACKNOWLEDGMENTS}

We thank Xiaolan Zhang and Jingnan Liang for their expert technical support.

\section{SUPPLEMENTARY MATERIAL}

The Supplementary Material for this article can be found online at: https://www.frontiersin.org/articles/10.3389/fimmu.2021.772189/ full\#supplementary-material

Supplementary Figure 1 | (A) Beta-diversity of colonic mucosa microbiota profiles of WT and Atg16L1 ${ }^{\text {T3O0A AT300A }}$ mice samples illustrated with PCOA using unweighted UniFrac distance metrics. Samples colored by different group: WT (green, $\mathrm{n}=8$ ); Atg16L1 ${ }^{\text {T300ATT300A }}$ (red, $\mathrm{n}=7$ ). The proportions of bacterial taxa in the colon (B) and ileum (C) mucosa were significantly differentially represented in WT mice vs. Atg16L1 ${ }^{\text {T300A } T 300 A}$ mice. Statistically significant differences were then evaluated by Tukey or Wilcoxon rank-sum post hoc tests. ${ }^{*} \mathrm{p}<0.05,{ }^{* *} \mathrm{p}<0.01$.

13. Erben U, Loddenkemper C, Doerfel K, Spieckermann S, Haller D, Heimesaat MM, et al. A Guide to Histomorphological Evaluation of Intestinal Inflammation in Mouse Models. Int J Clin Exp Pathol (2014) 7(8):4557-76.

14. Canny G, Swidsinski A, McCormick BA. Interactions of Intestinal Epithelial Cells With Bacteria and Immune Cells: Methods to Characterize Microflora and Functional Consequences. Methods Mol Biol (2006) 341:17-35. doi: 10.1385/1-59745-113-4:17

15. Salzman NH, Hung K, Haribhai D, Chu H, Karlsson-Sjoberg J, Amir E, et al. Enteric Defensins Are Essential Regulators of Intestinal Microbial Ecology. Nat Immunol (2010) 11(1):76-83. doi: 10.1038/ni.1825

16. Nowarski R, Jackson R, Gagliani N, de Zoete MR, Palm NW, Bailis W, et al. Epithelial IL-18 Equilibrium Controls Barrier Function in Colitis. Cell (2015) 163(6):1444-56. doi: 10.1016/j.cell.2015.10.072

17. Olli KE, Rapp C, O'Connell L, Collins CB, McNamee EN, Jensen O, et al. Muc5ac Expression Protects the Colonic Barrier in Experimental Colitis. Inflamm Bowel Dis (2020) 26(9):1353-67. doi: 10.1093/ibd/izaa064

18. Lapaquette P, Darfeuille-Michaud A. Abnormalities in the Handling of Intracellular Bacteria in Crohn's Disease. J Clin Gastroenterol (2010) 44 (Suppl 1):S26-9. doi: 10.1097/MCG.0b013e3181dd4fa5

19. Lavoie S, Conway KL, Lassen KG, Jijon HB, Pan H, Chun E, et al. The Crohn's Disease Polymorphism, ATG16L1 T300A, Alters the Gut Microbiota and Enhances the Local Th1/Th17 Response. Elife (2019) 8:e39982. doi: 10.7554/ eLife.39982

20. Veiga P, Gallini CA, Beal C, Michaud M, Delaney ML, DuBois A, et al. Bifidobacterium Animalis Subsp. Lactis Fermented Milk Product Reduces Inflammation by Altering a Niche for Colitogenic Microbes. Proc Natl Acad Sci USA (2010) 107(42):18132-7. doi: 10.1073/pnas.1011737107

21. Png CW, Linden SK, Gilshenan KS, Zoetendal EG, McSweeney CS, Sly LI, et al. Mucolytic Bacteria With Increased Prevalence in IBD Mucosa Augment In Vitro Utilization of Mucin by Other Bacteria. Am J Gastroenterol (2010) 105(11):2420-8. doi: 10.1038/ajg.2010.281

22. Conrad MA, Wu GD, Kelsen JR. The Gut Microbiota and Inflammatory Bowel Disease. In: Mamula P, Grossman AB, Baldassano RN, Kelsen JR, Markowitz JE, editors. Pediatric Inflammatory Bowel Disease. Cham: Springer International Publishing (2017). doi: 10.1007/978-3-319-49215-5_4

23. Kozik AJ, Nakatsu CH, Chun H, Jones-Hall YL. Comparison of the Fecal, Cecal, and Mucus Microbiome in Male and Female Mice After TNBS-Induced Colitis. PloS One (2019) 14(11):e0225079. doi: 10.1371/journal.pone.0225079 
24. He B, Xu W, Santini PA, Polydorides AD, Chiu A, Estrella J, et al. Intestinal Bacteria Trigger $\mathrm{T}$ Cell-Independent Immunoglobulin A(2) Class Switching by Inducing Epithelial-Cell Secretion of the Cytokine APRIL. Immunity (2007) 26(6):812-26. doi: 10.1016/j.immuni.2007.04.014

25. Brown EM, Ke X, Hitchcock D, Jeanfavre S, Avila-Pacheco J, Nakata T, et al. Bacteroides-Derived Sphingolipids Are Critical for Maintaining Intestinal Homeostasis and Symbiosis. Cell Host Microbe (2019) 25(5):668-80.e7. doi: 10.1016/j.chom.2019.04.002

26. Reunanen J, Kainulainen V, Huuskonen L, Ottman N, Belzer C, Huhtinen H, et al. Akkermansia Muciniphila Adheres to Enterocytes and Strengthens the Integrity of the Epithelial Cell Layer. Appl Environ Microbiol (2015) 81 (11):3655-62. doi: 10.1128/AEM.04050-14

27. Derrien M, Belzer C, de Vos WM. Akkermansia Muciniphila and Its Role in Regulating Host Functions. Microb Pathog (2017) 106:171-81. doi: 10.1016/ j.micpath.2016.02.005

28. Man SM, Zhang L, Day AS, Leach S, Mitchell H. Detection of Enterohepatic and Gastric Helicobacter Species in Fecal Specimens of Children With Crohn's Disease. Helicobacter (2008) 13(4):234-8. doi: 10.1111/j.15235378.2008.00607.x

29. Jin G, Tang Q, Ma J, Liu X, Zhou B, Sun Y, et al. Maternal Emulsifier P80 Intake Induces Gut Dysbiosis in Offspring and Increases Their Susceptibility to Colitis in Adulthood. mSystems (2021) 6(2). doi: 10.1128/mSystems.01337-20

30. Berry D, Schwab C, Milinovich G, Reichert J, Ben Mahfoudh K, Decker T, et al. Phylotype-Level 16S rRNA Analysis Reveals New Bacterial Indicators of Health State in Acute Murine Colitis. ISME J (2012) 6(11):2091-106. doi: 10.1038/ismej.2012.39

31. Macchione IG, Lopetuso LR, Ianiro G, Napoli M, Gibiino G, Rizzatti G, et al. Akkermansia Muciniphila: Key Player in Metabolic and Gastrointestinal Disorders. Eur Rev Med Pharmacol Sci (2019) 23(18):8075-83. doi: 10.26355/eurrev_201909_19024

32. Zhai Z, Zhang F, Cao R, Ni X, Xin Z, Deng J, et al. Cecropin A Alleviates Inflammation Through Modulating the Gut Microbiota of C57BL/6 Mice With DSS-Induced IBD. Front Microbiol (2019) 10:1595. doi: 10.3389/ fmicb.2019.01595

33. Swidsinski A, Dorffel Y, Loening-Baucke V, Theissig F, Ruckert JC, Ismail M, et al. Acute Appendicitis Is Characterised by Local Invasion With Fusobacterium Nucleatum/Necrophorum. Gut (2011) 60(1):34-40. doi: 10.1136/gut.2009.191320

34. Vacca M, Celano G, Calabrese FM, Portincasa P, Gobbetti M, De Angelis M. The Controversial Role of Human Gut Lachnospiraceae. Microorganisms (2020) 8(4). doi: 10.3390/microorganisms 8040573

35. Caruso R, Mathes T, Martens EC, Kamada N, Nusrat A, Inohara N, et al. A Specific Gene-Microbe Interaction Drives the Development of Crohn's Disease-Like Colitis in Mice. Sci Immunol (2019) 4(34). doi: 10.1126/ sciimmunol.aaw4341

36. Olaisen M, Flatberg A, Granlund AVB, Royset ES, Martinsen TC, Sandvik AK, et al. Bacterial Mucosa-Associated Microbiome in Inflamed and Proximal Noninflamed Ileum of Patients With Crohn's Disease. Inflamm Bowel Dis (2021) 27(1):12-24. doi: 10.1093/ibd/izaa107

37. Jellbauer S, Raffatellu M. An Intestinal Arsonist: Pathobiont Ignites IBD and Flees the Scene. Gut (2014) 63(7):1034-5. doi: 10.1136/gutjnl-2013-305589

38. Derrien M, Vaughan EE, Plugge CM, de Vos WM. Akkermansia Muciniphila Gen. Nov., Sp. Nov., a Human Intestinal Mucin-Degrading Bacterium. Int $J$ Syst Evol Microbiol (2004) 54(Pt 5):1469-76. doi: 10.1099/ijs.0.02873-0

39. Alam A, Leoni G, Quiros M, Wu H, Desai C, Nishio H, et al. The Microenvironment of Injured Murine Gut Elicits a Local Pro-Restitutive Microbiota. Nat Microbiol (2016) 1:15021. doi: 10.1038/nmicrobiol.2015.21

40. Ansaldo E, Slayden LC, Ching KL, Koch MA, Wolf NK, Plichta DR, et al. Akkermansia Muciniphila Induces Intestinal Adaptive Immune Responses During Homeostasis. Science (2019) 364(6446):1179-84. doi: 10.1126/ science.aaw7479

41. Alvarado DM, Chen B, Iticovici M, Thaker AI, Dai N, VanDussen KL, et al. Epithelial Indoleamine 2,3-Dioxygenase 1 Modulates Aryl Hydrocarbon Receptor and Notch Signaling to Increase Differentiation of Secretory Cells and Alter Mucus-Associated Microbiota. Gastroenterology (2019) 157 (4):1093-108.e11. doi: 10.1053/j.gastro.2019.07.013
42. Grander C, Adolph TE, Wieser V, Lowe P, Wrzosek L, Gyongyosi B, et al. Recovery of Ethanol-Induced Akkermansia Muciniphila Depletion Ameliorates Alcoholic Liver Disease. Gut (2018) 67(5):891-901. doi: 10.1136/gutjnl-2016-313432

43. Everard A, Belzer C, Geurts L, Ouwerkerk JP, Druart C, Bindels LB, et al. Cross-Talk Between Akkermansia Muciniphila and Intestinal Epithelium Controls Diet-Induced Obesity. Proc Natl Acad Sci USA (2013) 110 (22):9066-71. doi: 10.1073/pnas.1219451110

44. Patel KK, Miyoshi H, Beatty WL, Head RD, Malvin NP, Cadwell K, et al. Autophagy Proteins Control Goblet Cell Function by Potentiating Reactive Oxygen Species Production. EMBO J (2013) 32(24):3130-44. doi: 10.1038/ emboj.2013.233

45. Lassen KG, Kuballa P, Conway KL, Patel KK, Becker CE, Peloquin JM, et al. Atg16L1 T300A Variant Decreases Selective Autophagy Resulting in Altered Cytokine Signaling and Decreased Antibacterial Defense. Proc Natl Acad Sci USA (2014) 111(21):7741-6. doi: 10.1073/pnas.1407001111

46. Johansson ME, Larsson JM, Hansson GC. The Two Mucus Layers of Colon Are Organized by the MUC2 Mucin, Whereas the Outer Layer Is a Legislator of Host-Microbial Interactions. Proc Natl Acad Sci USA (2011) 108 (Suppl 1):4659-65. doi: 10.1073/pnas.1006451107

47. Davis CW, Dickey BF. Regulated Airway Goblet Cell Mucin Secretion. Annu Rev Physiol (2008) 70:487-512. doi: 10.1146/annurev.physiol.70.113006.100638

48. Okumura R, Takeda K. Maintenance of Intestinal Homeostasis by Mucosal Barriers. Inflammation Regener (2018) 38:5. doi: 10.1186/s41232-018-0063-z

49. Melgar S, Karlsson L, Rehnstrom E, Karlsson A, Utkovic H, Jansson L, et al. Validation of Murine Dextran Sulfate Sodium-Induced Colitis Using Four Therapeutic Agents for Human Inflammatory Bowel Disease. Int Immunopharmacol (2008) 8(6):836-44. doi: 10.1016/j.intimp.2008.01.036

50. Donaldson GP, Lee SM, Mazmanian SK. Gut Biogeography of the Bacterial Microbiota. Nat Rev Microbiol (2016) 14(1):20-32. doi: 10.1038/nrmicro3552

51. Garrett WS, Gordon JI, Glimcher LH. Homeostasis and Inflammation in the Intestine. Cell (2010) 140(6):859-70. doi: 10.1016/j.cell.2010.01.023

52. Swidsinski A, Loening-Baucke V, Herber A. Mucosal Flora in Crohn's Disease and Ulcerative Colitis - An Overview. J Physiol Pharmacol (2009) 60(Suppl 6):61-71.

53. Nagayama M, Yano T, Atarashi K, Tanoue T, Sekiya M, Kobayashi $\mathrm{Y}$, et al. TH1 Cell-Inducing Escherichia Coli Strain Identified From the Small Intestinal Mucosa of Patients With Crohn's Disease. Gut Microbes (2020) 12(1):1788898. doi: 10.1080/19490976.2020.1788898

54. Hall AB, Yassour M, Sauk J, Garner A, Jiang X, Arthur T, et al. A Novel Ruminococcus Gnavus Clade Enriched in Inflammatory Bowel Disease Patients. Genome Med (2017) 9(1):103. doi: 10.1186/s13073-017-0490-5

55. Conway KL, Kuballa P, Song JH, Patel KK, Castoreno AB, Yilmaz OH, et al. Atg1611 Is Required for Autophagy in Intestinal Epithelial Cells and Protection of Mice From Salmonella Infection. Gastroenterology (2013) 145 (6):1347-57. doi: 10.1053/j.gastro.2013.08.035

56. Saitoh T, Fujita N, Jang MH, Uematsu S, Yang BG, Satoh T, et al. Loss of the Autophagy Protein Atg16L1 Enhances Endotoxin-Induced IL-1beta Production. Nature (2008) 456(7219):264-8. doi: 10.1038/nature07383

Conflict of Interest: The authors declare that the research was conducted in the absence of any commercial or financial relationships that could be construed as a potential conflict of interest.

Publisher's Note: All claims expressed in this article are solely those of the authors and do not necessarily represent those of their affiliated organizations, or those of the publisher, the editors and the reviewers. Any product that may be evaluated in this article, or claim that may be made by its manufacturer, is not guaranteed or endorsed by the publisher.

Copyright (c) $2022 \mathrm{Liu}, \mathrm{Gao}, \mathrm{Jia}, \mathrm{Lu}, \mathrm{Zhu}$ and Zhang. This is an open-access article distributed under the terms of the Creative Commons Attribution License (CC BY). The use, distribution or reproduction in other forums is permitted, provided the original author(s) and the copyright owner(s) are credited and that the original publication in this journal is cited, in accordance with accepted academic practice. No use, distribution or reproduction is permitted which does not comply with these terms. 